NBER WORKING PAPER SERIES

\title{
DOES VIRTUAL ADVISING INCREASE COLLEGE ENROLLMENT? EVIDENCE FROM A RANDOM ASSIGNMENT COLLEGE ACCESS FIELD EXPERIMENT
}

\author{
Meredith Phillips \\ Sarah J. Reber \\ Working Paper 26509 \\ http://www.nber.org/papers/w26509 \\ NATIONAL BUREAU OF ECONOMIC RESEARCH \\ 1050 Massachusetts Avenue \\ Cambridge, MA 02138 \\ November 2019
}

This research was supported by the Institute of Education Sciences, U.S. Department of Education, through Grant R305A110809. The project also made use of resources at the California Center for Population Research, UCLA, which is supported by infrastructure grant R24HD041022 from the Eunice Kennedy Shriver National Institute of Child Health and Human Development. The opinions expressed are those of the authors and do not represent views of the Institutes, the U.S. Department of Education, or the National Bureau of Economic Research. Phillips discloses that she co-founded EdBoost, the non-profit organization that developed and implemented the V-SOURCE intervention evaluated in this paper, and served on its board until 2011. We thank Tiffani Chin, EdBoost's Executive Director, for her collaboration on all aspects of this project and Benjamin Denckla for donating his time and expertise to developing technologies for administering aspects of the program. We are grateful to Niña Abonal and Sara Mousavi for managing participant recruitment and program delivery, and for advising students; Cinthia Loera and Alexandra Mendoza for supervising survey recruitment; Sarah Butner, Patrick Cremin, Matthew Curry, Kara Fung, Takako Kobayashi, Rebecca Lowry, Daniel Mather, and María Lucía Yanguas for research assistance; all of the advisors, survey callers, and recruiters; the districts and schools that agreed to participate; the California Student Aid Commission for sharing data with us; and all of the students who participated in this study. We also thank conference participants at the American Economic Association, American Educational Research Association, American Sociological Association, Association of Education Finance and Policy, Association for Public Policy Analysis and Management, Society for Research on Educational Effectiveness, and National Bureau of Economic Research, and seminar participants at Teachers College, RAND, UC Davis, UC Irvine, UCLA, UC Riverside, USC, and the University of Virginia for helpful feedback. We are grateful to Jeffrey Smith for his insightful comments as a discussant on an early draft and to Chris Avery, Darin Christensen, Pascaline Dupas, Sara Goldrick-Rab, Tom Kane, Bridget Long, Phil Oreopoulos, Lindsay Page, and Bruce Sacerdote for helpful conversations.

NBER working papers are circulated for discussion and comment purposes. They have not been peer-reviewed or been subject to the review by the NBER Board of Directors that accompanies official NBER publications.

(C) 2019 by Meredith Phillips and Sarah J. Reber. All rights reserved. Short sections of text, not to exceed two paragraphs, may be quoted without explicit permission provided that full credit, including (C) notice, is given to the source. 
Does Virtual Advising Increase College Enrollment? Evidence from a Random Assignment

College Access Field Experiment

Meredith Phillips and Sarah J. Reber

NBER Working Paper No. 26509

November 2019

JEL No. I23,I24,J24

\begin{abstract}
$\underline{\text { ABSTRACT }}$
This paper describes the effects of two variants of a virtual college-counseling intervention designed to reduce informational and social support barriers to college application and enrollment among socioeconomically disadvantaged students. Students who were randomly assigned to the program felt more supported during the college application process and applied more broadly to four-year colleges, but they were not more likely to be accepted or enroll. We show that treatment effects on intermediate outcomes were larger for the types of students we anticipated would most need additional support during the college application process and discuss why the program did not improve college enrollment, while some other similar-seeming programs have improved enrollment. We conclude that low-intensity programs may work for some students, but targeting can be difficult. And many students probably need in-person and more intensive help to increase four-year enrollments.
\end{abstract}

Meredith Phillips

University of California, Los Angeles

Luskin School of Public Affairs

Department of Public Policy

3250 Public Policy Building

Los Angeles, CA 90095

meredith.phillips@ucla.edu

Sarah J. Reber

University of California, Los Angeles

Luskin School of Public Affairs

Department of Public Policy

3250 Public Policy Building

Los Angeles, CA 90095

and NBER

sreber@ucla.edu

An online appendix is available at http://www.nber.org/data-appendix/w26509

A V-SOURCE Research Website is available at https://www.sarahreber.com/vsource 


\title{
Does Virtual Advising Increase College Enrollment? Evidence from a Random Assignment College Access Field Experiment
}

\author{
Meredith Phillips and Sarah Reber*
}

November 2019

\begin{abstract}
This paper describes the effects of two variants of a virtual college-counseling intervention designed to reduce informational and social support barriers to college application and enrollment among socioeconomically disadvantaged students. Students who were randomly assigned to the program felt more supported during the college application process and applied more broadly to four-year colleges, but they were not more likely to be accepted or enroll. We show that treatment effects on intermediate outcomes were larger for the types of students we anticipated would most need additional support during the college process and discuss why the program did not improve college enrollment, while some other similar-seeming programs have improved enrollment. We conclude that low-intensity programs may work for some students, but targeting can be difficult. And many students probably need in-person and more intensive help to increase four-year enrollments.
\end{abstract}

* UCLA and UCLA and NBER, respectively. This research was supported by the Institute of Education Sciences, U.S. Department of Education, through Grant R305A110809. The project also made use of resources at the California Center for Population Research, UCLA, which is supported by infrastructure grant R24HD041022 from the Eunice Kennedy Shriver National Institute of Child Health and Human Development. The opinions expressed are those of the authors and do not represent views of the Institutes or the U.S. Department of Education. Phillips discloses that she co-founded EdBoost, the non-profit organization that developed and implemented the V-SOURCE intervention evaluated in this paper, and served on its board until 2011.

We thank Tiffani Chin, EdBoost's Executive Director, for her collaboration on all aspects of this project and Benjamin Denckla for donating his time and expertise to developing technologies for administering aspects of the program. We are grateful to Niña Abonal and Sara Mousavi for managing participant recruitment and program delivery, and for advising students; Cinthia Loera and Alexandra Mendoza for supervising survey recruitment; Sarah Butner, Patrick Cremin, Matthew Curry, Kara Fung, Takako Kobayashi, Rebecca Lowry, Daniel Mather, and María Lucía Yanguas for research assistance; all of the advisors, survey callers, and recruiters; the districts and schools that agreed to participate; the California Student Aid Commission for sharing data with us; and all of the students who participated in this study. We also thank conference participants at the American Economic Association, American Educational Research Association, American Sociological Association, Association of Education Finance and Policy, Association for Public Policy Analysis and Management, Society for Research on Educational Effectiveness, and National Bureau of Economic Research, and seminar participants at Teachers College, RAND, UC Davis, UC Irvine, UCLA, UC Riverside, USC, and the University of Virginia for helpful feedback. We are grateful to Jeffrey Smith for his insightful comments as a discussant on an early draft and to Chris Avery, Darin Christensen, Pascaline Dupas, Sara Goldrick-Rab, Tom Kane, Bridget Long, Phil Oreopoulos, Lindsay Page, and Bruce Sacerdote for helpful conversations. 


\section{INTRODUCTION}

Despite well-documented and growing benefits of a college education, youth from socioeconomically disadvantaged families are far less likely to attend college than their more advantaged peers (Baum, Ma, and Payea 2013; Bozick and Lauff 2007). ${ }^{1}$ Large and persistent social class disparities in college attendance among students with similar academic preparation suggest that low-income students face more barriers to college attendance than their higher-income peers. These college enrollment disparities, in turn, affect intergenerational mobility, economic inequality, and economic growth. This paper evaluates a relatively low-cost intervention designed to address these disparities.

A large majority of American teenagers, including those from low-income backgrounds, aspire to attend college (Ingels and Dalton 2013; Jacob and Linkow 2011), but many fewer enroll. Successfully applying to college and for financial aid-and ultimately enrolling and persisting in college-is a complex process. Students need to learn about various college options, where they might be competitive for admission, and how to register for, pay for, and study for standardized tests. If their school does not offer the SAT or ACT onsite, students need to get to a testing center. They need to understand how much attending college might cost, how they can pay for it, and how to apply for financial aid. Although colleges waive application fees for low-income students, students may not know about that policy. Finally, students need to successfully complete and submit college applications and financial aid forms, the latter with the help of a parent. To successfully apply to college, students must decide where to apply and then keep track of and complete many tasks by specific deadlines. This process is particularly unforgiving in California, the location of our study. For example, students are eligible for admissions to a four-year public college only if they earned at least a " $\mathrm{C}$ " in a specific set of college preparatory courses. In addition, four-year college application deadlines are early, no public four-year colleges have rolling admissions, and financial aid deadlines are firm.

EdBoost Education, a Los Angeles-based non-profit, developed the Virtual Student Outreach for College Enrollment (V-SOURCE) program to provide low-income students with more of the information, reminders, and support for applying to college that middle- and higher-income students tend to receive. The program, which drew on earlier college access interventions and insights from the social and behavioral sciences, delivered its services virtually, making it logistically and financially easier to scale compared to many existing college access programs. Because V-SOURCE was designed to provide assistance to students from families that had less experience with the college application and enrollment process, we recruited study participants from schools that were predominantly low-income and/or Hispanic/African American. The more than 6,500 students who participated in the study were mostly female (approximately 70 percent), second-generation immigrants (65 percent were U.S. born and had at least one foreign-born parent), and about half of the participants came from Hispanic, Spanish-speaking homes. Nearly 40 percent had parents who had not completed high school, and 75 percent had self-reported grade point averages of 3.0 or higher.

We randomly assigned these students to a "business as usual" control group or to one of two nested variants of a 15-month college counseling intervention. Students assigned to the Milestones variant

\footnotetext{
${ }^{1}$ For reviews of the literatures on the returns to education, including the extent to which returns vary across students, see Barrow and Malumud (2015), Card (2001), Hout (2012), and Oreopoulos and Petronijevic (2013).
} 
received access to a comprehensive website; emails and text messages sent several times a month with information tailored to the timing of particular college access activities and reminders about important deadlines, as well as links to relevant content on the website; and \$20 electronic gift card rewards for completing four key milestones in the college application process. Students assigned to the Complete variant received everything in the Milestones variant plus access to a personal advisor who communicated with the students through emails, texts, phone, and social media.

Students assigned to both variants of the V-SOURCE program reported that they felt more informed and supported during the college and financial aid application process than students assigned to the control group, and these point estimates were largest for students assigned to the Complete program (the variant with the personal advisor). The intervention had small impacts on SAT-taking and Free Application for Federal Student Aid (FAFSA) completion and broadened students' application portfolios. Students assigned to both variants of the program were more likely to apply to a four-year college, compared to the control group; and those assigned to the Complete program were more likely to apply to a selective college.

Although V-SOURCE increased students' completion of important milestones in the college application process, those improvements were modest and did not translate into higher four-year college acceptance rates or enrollment rates in the full sample. Our sample is large enough that we can rule out increases in four-year college enrollment, measured using administrative data from the National Student Clearinghouse, as small as 2.7 and 3.2 percentage points at the top of the 95 percent confidence interval for Milestones and Complete, respectively.

The results suggest, however, that V-SOURCE was effective for Hispanic students from Spanish-speaking families, a key sub-group targeted by the study based on prior research. These students, whose parents were predominantly immigrants with no college experience themselves, experienced larger treatment effects across a number of outcomes, including measures of feeling informed and supported during the college application process, applying to at least one four-year college, applying to at least one selective college, being accepted to a University of California (UC) campus (which are generally the more selective and better-resourced public colleges in California), and enrolling and persisting at a UC campus (though the enrollment and persistence estimates are statistically insignificant after adjustment for multiple comparisons).

After presenting the main impact analyses, we draw on our extensive survey data to situate our findings in the broader college access literature and to try to understand why the program did not have the intended effects on four-year college enrollment. While necessarily more speculative than the main treatment effects estimates, these analyses provide some insight into the barriers disadvantaged students face in enrolling in college and how college access programs work, or don't work, to address them.

We conclude from these analyses that the program operated largely as we had expected. The program increased students' applications to four-year and selective colleges, especially among the types of students it was designed to help: those whose parents could not help them with their applications (see also, Carrell and Sacerdote 2017) and those who tended to be disorganized and procrastinate. The pattern of effects for college applications by baseline grade point average (GPA) also suggests that the program broadened students' application portfolios in ways that were consistent with their academic background. But these effects on college applications were not large enough to increase enrollment. 
Past studies that found effects of near-peer or professional college advising services on college enrollment used in-person advisors to assist students (e.g., Avery 2013; Barr and Castleman 2018; Bos et al. 2012; Carrell and Sacerdote 2017). Thus, we speculate that V-SOURCE, because of its virtual nature, lacked key components that make in-person interventions more effective.

The results also indicate that positive selection into the study and the availability of alternative programs and sources of information and support may have reduced the scope for V-SOURCE to improve outcomes. The control means for some intermediate outcomes, particularly on-time FAFSA completion, were higher than expected. Nevertheless, about half of control students, many of whom appear to have been academically prepared for a four-year college, did not enroll in a four-year college, so there was scope for improvement.

Together with the literature, our findings suggest that navigating the complex process of transitioning from high school to college is too difficult for many adolescents to accomplish without significant support. While inexpensive interventions focused primarily on the college application process have helped some students enroll in college, such programs can be difficult to target, and the availability of alternative sources of information and help may limit the measured impact of any one program. Ultimately, many low-income students will likely need more hands-on help with the application process or more intensive and expensive interventions addressing fundamental financial, academic, and institutional barriers to successfully enroll in and complete college.

\section{BACKGROUND}

\subsection{Socioeconomic DisPaRITIES In ColLEge ACCESS}

Social class disparities in academic preparation are the most important proximate cause of social class disparities in college enrollment and success, and these disparities emerge long before most college access programs begin (Klasik 2012; Phillips 2011). Yet socioeconomically disadvantaged students who are as well-prepared academically as their more advantaged counterparts nonetheless attend college at substantially lower rates (Bailey and Dynarski 2011; Ellwood and Kane 2000; Klasik 2012; Phillips 2011). Theoretical perspectives from economics, sociology, and psychology provide a number of plausible explanations for these remaining disparities in college enrollment and thus suggest types of interventions that might reduce them (see Perna 2006, for a review).

Becker's (1993) human capital model suggests that students will attend college if the perceived benefits exceed the perceived costs. This implies that socioeconomic disparities in college going could arise if the actual or perceived costs and benefits of college attendance differ by socioeconomic status. Convenience samples suggest that students' perceptions of the economic returns to college do not differ by social class (see, e.g., Avery and Kane 2004; Rouse 2004). Students and parents from all backgrounds tend to overestimate the cost of college (Avery and Kane, 2004; Grodsky and Jones 2007), which likely matters more for low-income students. Moreover, Dynarski and Scott-Clayton (2013) argued that it may be more difficult than in the past for low-income families to know how much college will cost them as posted tuitions and net costs increasingly diverge for low-income students. Although student loans are available and the returns to college likely justify their use, credit constraints and debt 
aversion may also contribute to social class disparities in college-going (Dynarski and Scott-Clayton 2013; Olson and Rosenfeld 1984; Perna 2008).

To understand these disparities, sociologists draw on the status attainment model, which suggests that students from disadvantaged family backgrounds complete less schooling, in part, because they have lower educational expectations and receive less support for college-going from their parents, peers, and teachers (see, e.g., Sewell and Hauser 1972). Theories about the importance of social and cultural capital (Bourdieu 1984; Coleman 1988) also emphasize the role of families and schools in shaping students' sense of which educational paths are possible, reasonable, or assumed (Bourdieu and Passeron 1977; Horvat 2001; McDonough 1997), as well as in providing personalized and detailed information about college and financial aid options (e.g., Lareau and Weininger 2008; Plank and Jordan 2001).

According to these perspectives, middle class students are steeped in a college-going culture from an early age and take for granted that they will attend college (Grodsky and Riegle-Crumb 2010). Typically, their parents, and often their grandparents, attended college and have the know-how to help them navigate the process of preparing academically for college and applying (Buchman, Condron, and Rocigno 2010). More advantaged students are more likely to attend high schools in which going to college and receiving help with the process are the norm. In contrast, disadvantaged students are more likely to attend schools with a weak college-going culture and overwhelmed counselors (McDonough 2004; Robinson and Roksa 2016; Roderick, Coca, and Nagaoka 2011; Stephan and Rosenbaum 2013), and their parents, having not attended college themselves, may be poorly positioned to help.

Finally, research in psychology and behavioral economics suggests that parental or institutional support for the college application process may be particularly useful because applying to college and for financial aid requires filling out complicated forms by firm deadlines, and improving one's chances of admission can require studying for the SAT or drafting multiple versions of college essays. Considering that adults often avoid unpleasant tasks that are in their long-term best interest, such as planning for retirement (Beshears et al. 2008; Laibson 1997; Madrian and Shea 2001), and that adolescents are likely more myopic and have less self-control than adults (Steinberg et al. 2009), it is not surprising that many adolescents need considerable encouragement for and support with the college application process. Social class disparities may then arise if low-income adolescents face additional bureaucratic hurdles (such as the financial aid process) and have fewer sources of support for the process (Avery and Kane 2004; Bettinger et al. 2012; Dynarski and Scott-Clayton 2006).

\subsection{EfFEcts OF COLLEGE ACCESS InTERVENTIONS}

Prior studies show that some relatively low-intensity college access programs that reduce one or more of these presumed barriers can increase four-year college enrollment among disadvantaged students. ${ }^{2}$ We summarize these studies in Appendix A. For example, interventions where tax preparers completed the FAFSA (Bettinger et al. 2012) or where near-peers helped students complete college applications (Carrell and Sacerdote 2017) increased four-year college enrollment substantially. Other low-cost interventions that primarily provided information, particularly about the likely cost of attendance, induced high-achieving low-income students to enroll in more selective colleges (Dynarski et al. 2018; Hoxby and Turner 2013).

\footnotetext{
${ }^{2}$ See Page and Scott-Clayton (2016) and French and Oreopoulos (2017) for more detailed reviews of this literature.
} 
Interventions providing information, reminders, and some support during the summer before college have helped students follow through on their college enrollment intentions-reducing the extent to which students who have been admitted to college fail to enroll in the fall ("summer melt") (Castleman and Page 2014; Castelman, Page, and Schooley 2014). However, other relatively inexpensive college access interventions have not improved four-year college enrollment. For example, a state-wide Michigan program successfully encouraged students to seek college application information online but did not affect enrollment (Hyman 2019), and a large-scale FAFSA intervention-which included an arm in which students had access to one-on-one FAFSA advising-did not affect enrollment (Bird et al. 2019). Several recent evaluations of interventions targeting primarily high-achieving, low-income students, similar to the population in Hoxby and Turner (2013), found little or no effect on college enrollment, though they found small effects on the type of college where students enrolled (Gurantz et al. 2019; Sullivan 2019). An evaluation of a low-cost school-wide, in-school, near-peer advising intervention found small effects on two-year enrollment and no effects on four-year enrollment (Bettinger and Evans 2019). Similarly, the evaluation of a low-cost school-wide intervention that provided in-class workshops, with in-person support to complete applications, found effects on two-year enrollment but not four-year enrollment (Oreopoulos and Ford 2019). In contrast, studies of some more-expensive, in-person college access interventions found larger effects on four-year enrollment (Avery 2013; Barr and Castleman, 2019; Sacerdote and Carrell 2017).

Most relevant to this study is the Student Outreach for College Enrollment (SOURCE) program. EdBoost - the organization that implemented VSOURCE-developed and implemented SOURCE in the Los Angeles Unified School District (LAUSD) in 2006-2007. ${ }^{3}$ SOURCE provided students who were on track to be eligible for admission to a four-year public university with a near-peer advisor, with the goal of increasing four-year college enrollment. Bos et al. (2012) reported that SOURCE increased enrollment at four-year colleges by 3.5 percentage points overall (significant at the 10 percent level), with larger, statistically significant effects for Spanish-speaking students (10 percentage points) and students whose parents did not attend college (6 percentage points). SOURCE cost about $\$ 1,000$ per student in 2006. We hypothesized that a less expensive, completely virtual version of SOURCE might also boost four-year college enrollment. Because it would not require near-peer advisors to be proximate to students, such a program could be more easily and cheaply scaled. ${ }^{4}$

\footnotetext{
${ }^{3}$ SOURCE was based conceptually on the Boston College Opportunity and Career Help (COACH) program, which brought Harvard students to three Boston high schools to help high school seniors with college and financial aid applications (Avery and Kane 2004).

${ }^{4}$ A growing literature examines the effects of relatively "low-touch" interventions at all levels of education, intervening with both parents and students, with mixed results. Although a full review of these studies is beyond the scope of this paper, we note a few general patterns. Programs that provide information to parents, often by text message-about their children's attendance or performance in school (e.g., Bergman and Chan 2019; Robinson et al. 2018; Rogers and Fellers 2018; Kraft and Dougherty 2013) or encouraging literacy activities (Cabell et al. 2019; Mayer et al. 2018; York, Loeb, and Doss 2019) - have been successful at low cost. Interventions designed to improve study habits or effort by providing information or automated/virtual substitutes for traditional student support programs in secondary schools (Fryer 2016) and college (e.g., Oreopoulos and Petronijevic 2018; Oreopoulos et al. 2018) have had more limited success. Providing information about federal loans for which community college students were eligible increased borrowing and improved college outcomes substantially (Marx and Turner 2019), whereas providing information about substantial tax benefits of college attendance did not (Bergman, Denning, and Manoli 2019).
} 


\section{THE INTERVENTION}

\subsection{Program Design}

We collaborated with EdBoost to revise the SOURCE program to both add additional components and to make it less expensive and easier to scale. Given limited sample size and resources, we chose to test two coherent interventions rather than have many treatment arms designed to test specific theories about barriers to college-going. We nested the two treatments so that the evaluation could distinguish the impact of having access to a personal (virtual) advisor (V-SOURCE Complete) from the impact of a less expensive, fully-automated variant (V-SOURCE Milestones). The interventions lasted from March of students' junior year in high school through the summer following their senior year, providing information and support for all aspects of the college and financial aid application process. ${ }^{5}$

Table 1 describes the components of each variant of V-SOURCE; see Phillips and Reber (2019) for more detail on V-SOURCE program components and program implementation. Students assigned to both variants received: (1) access to the V-SOURCE website, which included information on all aspects of the college and financial aid application process; (2) access to the online Ready, SAT, Go! curriculum, which was targeted toward lower-scoring students compared to existing SAT study programs ${ }^{6}$; $(3)$ information and reminders sent weekly via email and text messages, with changing content tailored to the specific phase of the college and financial aid application process; and (4) Milestone Rewards (\$20 electronic gift cards) for completing four key milestones in the process-registering for the SAT, taking the SAT, submitting two college applications to different systems, and submitting the FAFSA (or DREAM Act Application) on time. These gift card rewards were designed to signal the importance of completing each of these steps and to reduce procrastination. In addition to all of these automated components, students in the Complete program received an advisor who was available to help them personally (via phone, email, text, social media) with all aspects of the college and financial aid application process. We estimate that the program cost about $\$ 84$ and $\$ 529$ per participant for the Milestones and Complete variants, respectively; this includes some fixed costs, so costs could be lower, especially for Milestones, at a larger scale. ${ }^{7}$

\subsection{Take-Up and Program Use}

All students assigned to the intervention groups had access to the program components summarized in Table 1, but this does not mean they used the program. We collected administrative data on program use and surveyed students in the late spring of their senior year about program use; we reported extensively on those data in Phillips and Reber (2019). We summarize those findings here to give the

\footnotetext{
${ }^{5}$ We randomly varied the post-high school summer portion of the program so that for one-third of students, the program concluded in June after high school graduation; another third received automated messages (and in the case of V-SOURCE Complete, access to help) about tasks they needed to complete during the summer; and the final third received all of the information contained in the summer messages (and in the case of V-SOURCE Complete, an offer of access to help) in a single email at the start of the summer. All students continued to have access to the V-SOURCE website during the summer.

${ }^{6}$ Commercially available SAT preparation materials, such as those produced by Princeton Review and Kaplan, are designed for students with higher scores and proved difficult for SOURCE participants to use.

${ }^{7}$ See Phillips and Reber (2019) for details on how we estimated program costs.
} 
reader an idea of the bundle of services - the "dose" - that the typical student assigned to the intervention received.

Students did not have to actively enroll in the program to receive services, so we do not have a traditional measure of program enrollment. Instead, we construct a measure of program take-up based on the administrative program use data, which shows that nearly all students offered the intervention knew they had access to and had at least some contact with the program. Table 2 shows that 92 percent of students assigned to Milestones and 99 percent of those assigned to Complete had at least one confirmed contact with V-SOURCE, ${ }^{8}$ and nearly all (96 percent) students assigned to Complete had at least one interaction with their advisor after the program's introductory period.

Table 2 also summarizes the average amount of services that students received through the program and how helpful they perceived it to be. V-SOURCE sent students in both Milestones and Complete an average of four automated emails and three to four automated text messages per month. The typical participant did not visit the website a lot, despite texts and emails that included links directing students to relevant webpages. Students assigned to Complete visited the website on 8.3 distinct days, compared to 5.6 distinct days for Milestones. Students in Milestones and Complete claimed 1.4 and 1.8 Milestone Rewards (\$20 electronic gift cards for completing key steps in the college application process), respectively. The data suggest that about 10 to 20 percent of students used the SAT study materials at least a moderate amount. ${ }^{9}$

On average, students assigned to the Complete program texted or emailed back-and-forth with their advisor about eleven times during the 15 months of the program, talked to their advisor by phone nearly twice, and received about 50 group emails sent by their advisor and another eight emails sent to them personally. The data suggest that students in Complete used the automated components of the program (the website, SAT materials, and Milestone Rewards) more than students in Milestones, most likely because the advisors encouraged students to use other components of the program.

The self-reported data on program use show patterns that are broadly consistent with the administrative data, but students appear to over-report their use somewhat. Overall, students found most components of the program helpful; more than 75 percent of participants in both Milestones and Complete found the V-SOURCE website and emails "helpful" or "very helpful," and more than 85 percent of those in Complete found their advisor "helpful" or "very helpful" (Table 2).

\footnotetext{
${ }^{8}$ This variable is equal to 1 if the student actively interacted with the program at any point, including replying to an email or text message, claiming a Milestone Reward gift card, interacting with their advisor or a program coordinator, or logging into the website (even if only to visit an administrative page). In addition, several weeks after we informed students that they were in the program, we did an "outreach" campaign to confirm that students assigned to V-SOURCE Complete or Milestones knew that they had access to the program. We first sent automated emails and text messages asking for a confirmation reply; advisors and program staff then reached out by phone to students who did not respond to the email and text messages. "Any Confirmed Contact" is also equal to 1 for students who confirmed they knew they had access to the program during this outreach.

${ }^{9}$ For example, about 8.5 percent of Milestones and 11.3 percent of Complete students received a "Bronze Medal" for completing at least ten quizzes with at least 80 percent correct; and about 17.7 and 24.8 percent of Milestones and Complete students, respectively, visited SAT study materials on more than 5 separate days. See Phillips and Reber (2019) for more details.
} 
To summarize, nearly all students assigned to treatment knew they were in the program and used at least some services, and some students received substantial services; the average student received a moderate dose of services. Students assigned to Complete typically had multiple personalized electronic communications with their advisors and a couple of phone calls, and some had much more intensive help from their advisors. For some students, particularly those enrolled in Milestones, the treatment mostly consisted of the automated emails and text messages and the offer of Milestones Rewards.

\section{DATA AND MethodS}

\subsection{Participant Recruitment And SAMple}

Because the program began in the spring of students' junior year, V-SOURCE targeted students who were likely to be eligible for admission to public four-year colleges in California based on their prior grades and course-taking. To recruit students to the study, we develop a list of relatively large, comprehensive high schools in six southern and central California counties that predominantly served low-income students of color. ${ }^{10}$ Some eligible schools did not respond to calls or declined to participate, but the recruited schools were similar to the eligible pool on most key variables (Table C.1). In the fall of the 2011-12 and 2012-13 school years, EdBoost provided high school juniors at participating schools with a free application that collected information on students' backgrounds, course taking, and grades, so that we could determine their academic eligibility for the program.

Table 3 shows that, as intended, the program recruited students who were socio-economically disadvantaged. Approximately 60 percent of students had parents who had not attended college at all. Just over half of the students reported "using lunch tickets," which is likely an underestimate of actual subsidized meal eligibility because some schools have school-wide meal programs (so students don't use lunch tickets), students may choose not to report their lunch ticket use, and some who receive tickets do not use them. The program attracted more girls than boys ( 68 percent), consistent with girls' significantly higher college-going rates, more Hispanic students than any other ethnic group (approximately 75 percent of participants, and approximately 70 percent of whom reported speaking Spanish with their parents), and mostly U.S.-born students whose parents were foreign-born.

Participants had relatively high grade point averages (about 75 percent reported B averages or above) and very high educational aspirations (nearly 80 percent aspired to a graduate degree).

Table 4 shows that at the time students applied to the program, they were relatively active users of the Internet, email, and text messaging - the three key technologies used to deliver the program. Eighty-one percent reported using the Internet at least a few times a week on their own computer, and 97 percent

\footnotetext{
${ }^{10}$ We targeted comprehensive high schools where at least 60 percent of the students were African American and/or Hispanic/Latino (AA/HL) and where at least 60 percent qualified for free or reduced-price meals (FRPM). We prioritized schools with more than 200 juniors, and recruiting staff attempted to contact all schools that met these three criteria. Recruiting staff also contacted additional schools meeting slightly relaxed criteria at their discretion if it made logistical sense to recruit there. These included smaller schools meeting the 60 percent AA/HL and 60 percent FRPM thresholds. Schools meeting either the AA/HL or FRPM cutoffs at a 50 percent threshold and smaller "schools within schools" sharing a campus with an eligible school. In practice, the vast majority of research participants were enrolled in schools satisfying the first set of criteria. See Phillips and Reber (2019) for more details on school and participant recruitment procedures.
} 
reported using the Internet that often by any method. Eighty-one percent reported checking their email a few times a week, and 96 percent reported checking it at least a few times a month. Eighty-three percent reported text messaging at least a few times a week. Although technology use was slightly higher among students with more highly-educated parents, the vast majority of students who participated in the study had access to the technologies they needed to use the V-SOURCE program.

\subsection{SURVEY DATA}

A key advantage of our study is that we not only have administrative data on college enrollment and financial aid application, but also extensive survey data on baseline characteristics, intermediate outcomes, and students' self-reported experiences applying to college. We surveyed participants three times during the study. As part of students' application to the program, we administered a short, paper survey that asked about students' course-taking and grades (to determine their eligibility), demographic and family background, technology use, and self-perceptions. Prior to random assignment, we invited applicants to participate in a longer, online Baseline Survey that covered a wide range of topics, including demographic and family background, self-perceptions, and college knowledge and plans. In late spring/early summer of the senior year, we invited participants to take an online Follow-up Survey asking about their college preparation, college and financial aid applications, future plans, and, for students assigned to the program, their experiences with the program. ${ }^{11}$ Response rates varied across the cohorts and surveys but were generally high. The Application Survey had a small number of items but a nearly 100 percent response on most items. Defined as answering at least 80 percent of items, we obtained response rates to the Baseline Survey of 77 and 94 percent for cohorts 1 and 2, respectively ( 87 percent overall), and to the Follow-up Survey of 87 and 88 percent, respectively. ${ }^{12}$

\subsection{College Enrollment And Financial Aid Administrative Data}

Our key outcomes of interest are whether and where students enrolled in college in the fall after expected high school graduation and whether they persisted to the second fall. We use administrative data from the National Student Clearinghouse (NSC) to construct these variables. The NSC is a non-profit organization that provides enrollment and degree-verification services. Participating colleges and universities report their students' enrollment to the NSC, and the NSC makes these data available to researchers (see Dynarski, Hemelt, and Hyman 2013 for more details on the NSC data). The NSC matches students to their college enrollment records based on name and date of birth. ${ }^{13}$ The match is imperfect, but because we constructed the data we provided to the NSC for the match without regard to treatment

\footnotetext{
${ }^{11}$ We also administered a short survey only to the control group during the summer between junior and senior year. This survey served two purposes: (1) to improve our chances of getting a response to the Follow-up Survey by maintaining contact with students and updating their contact information, and (2) provide control group students an opportunity to receive a $\$ 20$ gift card to reduce demoralization since some knew students in the intervention groups and may have been disappointed that they didn't have a chance to get a gift card for completing college application milestones. In addition to updating their contact information, we asked a few questions about how they spent their summers, but we do not analyze these data as part of the research.

${ }^{12}$ Phillips and Reber (2019) describes in more detail how we administered the surveys and includes the surveys in an appendix.

${ }^{13}$ The NSC can, under some circumstances, match on students' social security number (SSN). We did not collect SSNs for fear of deterring potential applicants and because we expected students' reports of their SSNs to be inaccurate.
} 
status using only data collected prior to random assignment, matching imperfections should affect treatment and control groups similarly and should not bias our results. ${ }^{14}$ We linked the colleges in which students enrolled to data from the Integrated Postsecondary Education Data System (IPEDS) and constructed indicators for attending and persisting in different types of colleges.

We also obtained data related to financial aid application and receipt from the California Student Aid Commission (CSAC). CSAC used a matching procedure similar to that used by the NSC to find study participants in their database. In addition to information about whether and when students completed their financial aid paperwork, CSAC provides information on where students attended college if they used CalGrant funding at that college. We found that when both the NSC and CSAC matched a student to a college, the data were consistent in the vast majority of cases. ${ }^{15}$ For 9.7 percent of the sample, however, CSAC reported disbursing financial aid to a college for a student, even though the NSC did not find a match to a college for that student. These CSAC-reported enrollments appear to be largely valid enrollments that the NSC missed, so we created a second set of "CSAC augmented" college enrollment outcome variables. ${ }^{16}$ The CSAC augmented enrollment variables provide a more complete picture of college enrollment; however, CSAC reports only college enrollment conditional on receiving financial aid, which could be affected by the treatment. We therefore report results based on the NSC data only and present the CSAC augmented results in the Online Appendix.

\subsection{RANDOM ASSIGNMENT}

The V-SOURCE Milestones treatment was less expensive compared to V-SOURCE Complete so would be cost effective with smaller treatment effects. Thus, to improve power to detect small treatment effects

\footnotetext{
${ }^{14}$ Imperfect matches can arise because (1) participants with common names may match to multiple records, in which case the NSC does not return a match; (2) participants may report a different name to us than they use to register for college; (3) colleges sometimes do not report undocumented students to the NSC even when they are enrolled in college; and (4) some institutions do not participate in the NSC, so participants attending those institutions will not return a match (see National Student Clearinghouse Research Center 2014 ). In some research using the NSC data, NSC does not return a match for students who have opted to block disclosure of their directory information or for institutions that have blocked all of their students' directory information. Participants in our study consented to having their data matched, so the NSC provided a consent-based match, and this is not a limitation in our study.

${ }^{15}$ In 98.2 percent of cases where CSAC and NSC both report college attendance for a student, the two datasets are consistent. For many cases, NSC reports college enrollment, but CSAC does not; this is expected because CSAC names a college only if the student receives CalGrant aid there, and students may attend without CalGrant aid for a variety of reasons.

${ }^{16}$ Students might not appear in the NSC data for a variety of reasons. NSC searches a national database and does not return a match if the student matches to more than one observation in their database. The CSAC match was limited to the state of California and used the high school attended prior to random assignment to disambiguate matches. Our analysis also shows that undocumented students are over-represented in the group that attends college according to CSAC but does not attend college according to the NSC, suggesting the NSC disproportionately misses these students (see also National Student Clearinghouse Research Center, 2014). The NSC appears to miss a large share of enrollment among undocumented students, but undocumented students are a small share of our sample. We did not ask students if they were undocumented, but 84 percent of the sample is US-born, and the information we have suggests undocumented students are probably less than 10 percent of the full sample. Among the 16 percent of the sample that is foreign-born, 48 percent completed a FAFSA, indicating they have legal status; 34 percent completed a California DREAM Act application, indicating they are undocumented; and the remaining 18 percent did not fill out either form, so we do not know their status.
} 
in the Milestones treatment and stay within our budget, we chose to assign fewer students to V-SOURCE Complete than to the other two treatment arms. We planned to assign students to Complete, Milestones, and Control in a 2:3:3 ratio. However, we over-recruited slightly in cohort 2 and divided the extra students evenly between Milestones and Control. ${ }^{17}$

Because earlier randomized studies of college access programs found heterogeneous effects by gender, parental education, and/or race/ethnicity and home language, we randomly assigned students to each treatment within blocks created by fully interacting gender ( 2 categories: male and female), parental education ( 2 categories: at least one parent attended college, excluding vocational; and no parent attended college), and a race/ethnicity-home language composite (3 categories: Hispanic and speaks Spanish at home, Hispanic and does not speak Spanish at home, and all other students). The interaction of these categorical variables generated 12 blocks; we put students who had missing data on any of these variables in a separate block. ${ }^{18}$

We randomly assigned students rather than schools, despite concerns about within-school treatment diffusion or control group demoralization, because school-level assignment would have required an extremely large sample of schools to yield sufficient power. The Follow-up Survey included questions designed to assess the extent of diffusion and demoralization. These data suggest there was some diffusion to the control group, though we do not think it affected the control group very much overall (we discuss this further below). We do not find evidence that demoralization was a problem. ${ }^{19}$

Students were allowed to leave the research at any time, and 70 students (1.1 percent) did so after random assignment. The students who left the research all did so during survey administration periods, presumably because they did not want to be bothered with reminders to take the survey. We excluded these students from the analysis. Table C. 2 shows that participant characteristics measured prior to random assignment are balanced across the treatment and control groups in the analysis sample. ${ }^{20}$

\footnotetext{
${ }^{17}$ We excluded 59 students from the research prior to random assignment because they had poor contact information, so we had no way to reach them. To avoid problems in administering the program, we non-randomly assigned some students who were in the same household with another participant (typically twins) to the same treatment arm as their household-mate. We excluded the non-randomly assigned students from the analysis. See Phillips and Reber (2019) for more details.

${ }^{18}$ We coded the parental some college variable as 0 , rather than missing, if students reported that they didn't know their parents' education or didn't have that parent; we coded that variable as missing if the student didn't answer the question at all.

${ }^{19}$ On the Follow-up Survey, we asked students "Last March, when you were invited to [be in the V-SOURCE research group, in which you would be asked to take several surveys]/[to participate in V-SOURCE and given access to the vsource4college.org website], how did you feel?" with five response options (Very Happy, Somewhat Happy, Neither Happy nor Disappointed, Somewhat Disappointed, and Very Disappointed). Students assigned to either variant of the program were more likely to report that they were "Very Happy" and less likely to report that they were "Neither Happy nor Disappointed." Few students reported disappointment about their assignment to the control group: Only 0.7 percent and 0.6 percent of the control group reported they were "Somewhat Disappointed" or "Very Disappointed." See Phillips and Reber (2019).

${ }^{20}$ We regressed each variable on indicators for being assigned to Milestones or Complete and a Cohort 2 indicator (since the probabilities of being assigned to each treatment arm differ across cohorts). Column 1 shows the control mean, columns 2 and 3 show the coefficients on the Milestones and Complete indicators, respectively, and column 4 shows the $p$-value for the F-test of joint significance for the Milestones and Complete indicators. We find
} 


\subsection{ESTIMATION}

We estimate intent-to-treat (ITT) effects of assignment to V-SOURCE Complete or V-SOURCE Milestones, relative to the control group.

We estimate equations of the following form:

$$
\text { (1) } Y_{i s b}=\beta_{0}+\beta_{1} \text { MILESTONES }_{i s b}+\beta_{2} \text { COMPLETE }_{i s b}+X_{i s b} \beta_{3}+\eta_{b}+\varepsilon_{i}
$$

where $Y_{\text {isb }}$ is an outcome measure for student $i$ in school $s$ in block $b$ and MILESTONES and COMPLETE are mutually exclusive treatment group indicators; the omitted category is the control group. The parameters of interest are $\beta_{1}$ and $\beta_{2}$, indicating the effects of each treatment relative to the control group. $\eta_{b}$ is a set of block-group indicators (excluding one) to account for blocking during random assignment; note that these implicitly control for key demographic predictors of college-going outcomes and cohort. To further address potential imbalances due to chance or differential survey response (for the self-reported outcomes) ${ }^{21}$ and to improve power, we include in the main specification controls $(X)$ for a flexible function (cubic) of each of two measures of GPA collected on the Application Survey. ${ }^{22}$ The results are largely unaffected by the inclusion of these controls or controlling for additional baseline covariates. ${ }^{23}$ Finally, $\varepsilon_{i}$ is an individual-specific error term.

We also present estimates of heterogeneous treatment effects for the key demographic groups used to create the blocking groups and for some additional baseline characteristics of theoretical interest. We interact the Complete and Milestones treatment indicators with an exhaustive set of indicators for each category of the characteristic of interest. For example, the estimating equation for the analysis of treatment effects by gender is:

statistically significant differences for whether students were US Born (or US Born was missing), checking email a few times a week, and text message frequency missing. Those differences are substantively small.

${ }^{21}$ Although the response rate for the Follow-up Survey was high (about 87 percent), the response rate was about 3 percentage points higher in the control group than in the two treatment groups. Differential response rates were larger earlier in the survey administration window and converged as we contacted the intervention groups more by email, text message, and eventually phone, to remind them to take the survey. We speculate that the intervention students were slower to respond because they had received a lot of communication from the $V$ SOURCE program during the prior 15 months, so were likely less attentive to an individual message from V-SOURCE (even through it came from a different email address or phone number), particularly if they perceived the college application process to be over. Comparison of administrative and survey-reported outcomes suggests that there may have been small positive differential selection into survey taking in the intervention groups, so the effects on self-reported outcomes may be biased upward slightly.

${ }^{22}$ On the Application Survey, students were asked "If you had to apply to college today, what would your GPA be? Make your best guess if you are not sure." The survey also asked students to report their grades in several courses. We constructed a GPA measure based on those course grades, and we include a cubic function of both the selfreported GPA and the constructed GPA as controls.

${ }^{23}$ See Phillips and Reber (2019) for alternative results that 1) exclude controls for GPA and 2) include controls for a more extensive set of baseline characteristics measured prior to random assignment (locus of control index, hard worker index, procrastinator/disorganized index, four-year college confidence index, close family support for applying to college index, school support for applying to college index, college access program participation, parents' educational expectations, financial worries about college index). We list the specific items in each index and describe how we construct the indexes in Phillips and Reber (2019). We enter the controls flexibly (quintiles for index variables) and include a dummy variable for missing data. 
(2) $Y_{i s b}=\gamma_{0}+\gamma_{1 f} M_{I L E S T O N E S} S_{i s b} \times F_{E M A L E} E_{i s b}+\gamma_{2 f}$ COMPLETE $_{i s b} \times F E M A L E_{i s b}$

$+\gamma_{1 m} M_{I L E S T O N E S} S_{i s b} \times M A L E_{i s b}+\gamma_{2 m}$ COMPLETE $_{i s b} \times M A L E_{i s b}$

$+\mathrm{X}_{i s b} \gamma_{3}+\eta_{b}+\varepsilon_{i}$

Where $\gamma_{1 f}$ is the treatment effect of Milestones for females, $\gamma_{1 m}$ is the treatment effect of Milestones for males, $\gamma_{2 f}$ is the treatment effect of Complete for females, and $\gamma_{2 m}$ is the treatment effect of Complete for males. Note that the main effect (e.g., FEMALE indicator) is subsumed in the blocking group indicators; for groups where this is not the case, we explicitly include the main effects as controls.

\subsection{INFERENCE}

We cluster the standard errors at the high school level to account for the clustering of students within schools. ${ }^{24}$ We use stars to indicate statistical significance at conventional levels for individual coefficients. Because we test many comparisons, considering each test separately will lead us to reject the null hypothesis too frequently, conditional on the chosen significance threshold. ${ }^{25}$ Following Kling, Liebman, and Katz (2007), we construct indices of related outcomes to reduce the number of outcomes we are examining, particularly for the outcomes related to students' self-reported levels of information and support for applying to college, which are based on a large number of survey questions. However, many of our key outcomes have an intuitive scale (for example, SAT taking, college application, and college enrollment), and we want to examine the effects of the program on different margins, so we do not combine these in an index.

We differentiate between confirmatory and exploratory analyses (see, e.g., Bloom and Michalopoulos 2010; Schochet 2008). We treat analyses of average effects and analyses of heterogeneous effects on the characteristics we blocked on as confirmatory and analyses of heterogeneity by other characteristics as exploratory. For the confirmatory analyses, we use the Benjamini-Hochberg (1995) method to control the false discovery rate within each domain of particular types of outcomes. ${ }^{26}$ We apply the adjustment separately within each domain for the average treatment effects and separately within each domain across all the subgroups when we analyze heterogeneous treatment effects. For example, the "Application Experiences" domain has three outcomes. For the analysis of average treatment effects in

\footnotetext{
${ }^{24}$ Alternatively, we can include high school fixed effects. Abadie et al. (2017) argued that clustering on high school may not be appropriate in this case because random assignment was at the individual level. In practice, all of these approaches produce very similar standard errors.

${ }^{25}$ Specifying outcomes and sub-groups as part of a pre-analysis plan is common in medicine and increasingly common in economics. We began this work in 2011 and did not register a pre-analysis plan. The outcomes and sub-groups we consider for our confirmatory analyses are the ones we "pre-specified" as of interest in our choice of blocking variables and largely what we identified in our grant application: "To examine whether the treatment is more effective for particular sub-groups, we will also interact the treatment variables with the moderating variables described above, including gender, parental education, parental language, and time preferences, although power considerations will limit our ability to divide the sample too finely." After writing the grant application but before conducting the analysis, we decided to focus on demographic sub-groups only in the confirmatory sub-group analysis and use the baseline data we collected on academic achievement and a range of self-perception constructs to explore mechanisms.

${ }^{26}$ We classify the outcomes within the following domains corresponding to Tables 5 through 10: Application Experiences ( 3 outcomes), Milestone Completion (4 outcomes), College Application Portfolio (5 outcomes), College Acceptances (5 outcomes), College Enrollment (5 outcomes), and College Persistence (5 outcomes).
} 
this domain, we adjust for 6 comparisons (two treatments by three outcomes); in the confirmatory subgroup analyses (Appendix D), we adjust for 42 comparisons (two treatments, three outcomes, seven subgroups). In the tables, we denote with a dagger coefficients that are significant at the 5 percent level after applying the adjustment for multiple comparisons. For supplementary outcomes (Appendix C) and exploratory sub-group analyses (Appendix E), we do not apply the adjustment for multiple comparisons.

\section{Program Impacts: Average EfFECTS}

We hypothesize that any reduced-form effect of assignment to V-SOURCE on college enrollment would operate by affecting how informed and supported students were during the college and financial aid application process, which would, in turn, impact key intermediate outcomes, such as SAT/ACT taking, college applications and acceptances, and on-time FAFSA completion, which would then change whether and where students enrolled and persisted in college. We present estimates of ITT effects for each of these outcomes for the whole sample and then turn to sub-group analyses.

\subsection{InFORMATION AND SUPPORT FOR COLLEGE APPLICATION}

We included a number of questions on the Follow-up Survey to assess how much V-SOURCE increased the overall amount of information and support students had during the college and financial aid application process. These questions were purposefully not aligned with the V-SOURCE program content and were intended to capture the extent to which students sought out information about the college application process, felt informed about various aspects of the process, and felt supported during the process. We combined these items into three indices measuring each of these constructs - "Sought Information," "Had Information," and "Had Support" - and used the indices, rather than separate items, as measures of students' experiences of the college application process. ${ }^{27}$

Table 5 reports the effects of being assigned to V-SOURCE Milestones or Complete on these indices. VSOURCE did not affect-in either direction - the extent to which students sought information about applying to college or for financial aid. These estimates are reasonably precise: the 95 percent confidence interval rules out effects as large as 0.08 student-level standard deviations. V-SOURCE did, however, increase the extent to which students felt informed and supported, by 0.086 and 0.080 standard deviations, respectively, for Milestones and by 0.109 and 0.152 standard deviations, respectively, for Complete.

These results suggest that the Milestones components-the website and automated messages-made students in both treatment groups feel more informed and supported. The point estimate on feeling supported was almost twice as large for students assigned to the Complete program (0.152 standard

\footnotetext{
${ }^{27}$ Before constructing these indices, we conducted exploratory factor analyses of the items. Those analyses provided support for a two-factor solution (in which "Had Information" and "Had Support" items could be combined) and a three-factor solution in which they remained distinct. We opted for the three-factor solution based on the content of the questions (face validity) and hypotheses about different effects for V-SOURCE Milestones and Complete. We expected, for example, that differences between Milestones and Complete might be larger on the "Had Support" construct than on the "Had Information" construct because V-SOURCE Complete students received an advisor who could provide personalized support; investigating that hypothesis required keeping those indices separate. The "Had Information" and "Had Support" indices are highly correlated (.68). The "Sought Information" index is less highly correlated with the other two indices (.30 with each).
} 
deviations) as for those assigned to Milestones (.080 standard deviations), whereas the point estimates for feeling informed were similar in both treatment arms. This is consistent with the emphasis of the Milestones components on providing information and the advisor (available to students in Complete) providing support. It is perhaps surprising that Milestones had any positive effect on the "Had Support" construct, given that the questions underlying that measure asked whether the student had someone who would help them with various tasks, and students in the Milestones program did not have an advisor. This positive effect suggests that students interpreted the automated messages and website content as written by humans who intended to be supportive.

Both crowd-out (whereby students substitute V-SOURCE services for services they otherwise would have received from another source) and diffusion (whereby some treatment components diffuse to the control group such that they are partially treated) may have reduced the measured effects of being assigned to the intervention on the outcomes reported in Table 5, and by extension the college enrollment outcomes. Our analysis of data from the Follow-up Survey shows minimal evidence of crowd-out. For example, treated students were no less likely to be enrolled in other college access programs. However, it is still possible that V-SOURCE participants used alternative programs and services less intensively than they otherwise would have, in ways we cannot observe.

We do find some evidence of diffusion to the control group. For example, about a quarter of students reported that a treatment student told them what they were learning from V-SOURCE, and a similar share reported receiving forwarded emails from a V-SOURCE participant. ${ }^{28}$ However, we do not think that diffusion had a large impact on the control group overall because between 60 and 70 percent of the control students reported learning "nothing" or "very little" from the V-SOURCE website, emails, text messages, and other students in the program, and only 4 to 7 percent of control group students reported learning "a lot of things." Moreover, some components, such as the advisor and the Milestone Rewards could not diffuse. ${ }^{29}$

Overall, the estimates in Table 5 provide evidence that treated students felt more informed and supported in the process of applying to college, despite the potential for crowd-out and diffusion. However, the treatment-control differences were modest in size. (Most other studies of college access programs do not measure these outcomes, so we cannot compare these estimates to the literature.) These effects represent the "first stage" for estimating the effect of information and support on collegegoing, as opposed to the effect of being offered the V-SOURCE program per se. Although our analysis

\footnotetext{
${ }^{28}$ To limit diffusion to the control group, EdBoost altered how the program was implemented in some ways, relative to how it would have been implemented outside the context of a random-assignment study. For example, to prevent control group students from accessing the website, EdBoost required program students to login, which may have deterred some treatment students from using the website as much as they otherwise might have. About 17 percent of treated students reported that they did not use the website more because they had trouble logging in. In addition, EdBoost attempted to prevent information from spreading in school and through social networks, by keeping Facebook groups closed, for example. Outside the context of a randomized trial, the program would have instead tried to magnify its messages by deliberately using students' social networks (especially since the diffusion results indicate that students seemed to find the information valuable enough to share it). We suspect these attempts to minimize diffusion reduced the effectiveness of the intervention somewhat.

${ }^{29}$ We provide more detail on our analyses of crowd-out and diffusion in Phillips and Reber (2019).
} 
focuses mainly on the intent-to-treat effects of V-SOURCE, the estimated effects on students' perceptions of information and support provide context for interpreting the magnitudes.

\subsection{INTERMEDIATE OUTCOMES}

Table 6 shows the effects of assignment to V-SOURCE on the four milestones for which students could receive Milestone Rewards: registering for the SAT or ACT, taking the SAT or ACT, submitting college applications, and submitting the FAFSA (or DREAM Act Application) by the CalGrant deadline. The SAT, $A C T$, and college application measures come from the Follow-up Survey, and on-time FAFSA completion comes from administrative data. The effects are largely positive but small. The only effect that is statistically significant at the 5 percent level after adjusting for multiple comparisons is in column (3): students assigned to the Complete program were about 5 percentage points more likely than the control group to apply to at least two four-year college systems (of the three systems: UC, CSU, private).

The effects found for the self-reported measures could be biased upward if treated students inflated their reports of feeling informed and supported, or having completed certain milestones, to please the research team (either consciously or unconsciously) - what researchers call "demand effects" (Orne 1962; Zizzo 2010) or "reactivity" (Webb et al. 1966). Having both survey and administrative data on FAFSA completion reduces these concerns, however. Among students who had data for both selfreported and administrative measures, students' reported FAFSA completion rates were only slightly higher on the survey ( 86 percent) than in the administrative data ( 85 percent) and the point estimates on FAFSA completion were similar, regardless of the measure used (Table C.3).

Note that the control means in Table 6 are relatively high. For example, 83 percent of the control group reported taking the SAT or ACT (without which they are ineligible for admission to the UC system and face diminished opportunities in the CSU system), and 79 percent submitted the FAFSA on time according to the administrative data. These high control means, especially for the administratively measured FAFSA completion rate, suggest that a large fraction of participants in our study did not face these important barriers to college eligibility and affordability, a point to which we return in the discussion.

Table 7 reports effects of assignment to V-SOURCE on where students applied to college. Students reported on the Follow-up Survey which colleges they had applied to, and we coded these into categories using IPEDs and Barrons. Each outcome is an indicator for having reported applying to at least one: (1) four-year college; (2) selective four-year college, which we define as having a 2013 Barron's classification of "very competitive plus" to "most competitive"; (3) college in the California State University (CSU) system; and (4) college in the University of California (UC) system. The program encouraged students to apply broadly to four-year colleges and to include selective colleges if appropriate given their academic record. Most of the coefficients in Table 7 are positive and statistically significant (even after adjusting for multiple comparisons), indicating that V-SOURCE increased the number and breadth of applications participants submitted. These effects are relatively small, however, with the largest point estimate implying that V-SOURCE Complete increased students' applications to at least one UC by 4.4 percentage points.

Overall, these analyses suggest that the Complete program had larger effects than the Milestones program on the application portfolio. It is not surprising that the college application process would 
benefit from the more personalized advice that an advisor could provide by taking into account students' academic profiles and goals.

Table 8 shows that students' increased applications to four-year colleges did not translate, however, into a statistically significant impact on acceptances. The point estimates imply that students who were induced by the Complete program to apply to at least one CSU or at least one UC, were accepted at rates that are reasonable for each of those systems taken as a whole, ${ }^{30}$ but the effects on college application outcomes were not large enough to yield notable effects on college acceptances.

\subsection{College Enrollment And Persistence}

The ultimate goal of the V-SOURCE program was to increase enrollment and persistence in four-year colleges. Table 9 shows that the effects on enrollment were small and statistically insignificant, which is unsurprising in light of the small effects on college application and statistically insignificant effects on acceptances. ${ }^{31}$ The estimated effect of Milestones on enrolling in a UC is 1.6 percentage points and statistically significant at the 5 percent level, but it is not significant after adjusting for multiple comparisons. The Milestones point estimates suggest a shift from CSU to UC, though the change in CSU enrollment is not statistically significant. Table C. 4 shows that estimates based on the CSAC-augmented measure of college enrollment are substantively the same, though the somewhat higher control means for the CSAC augmented measures (e.g., 52 percent vs 43 percent for four-year enrollment) are probably a more accurate portrayal of counterfactual enrollments.

The effects of the program on college enrollment are reasonably precisely estimated, allowing us to rule out effects on any four-year college enrollment larger than about 2.7 and 3.2 percentage points for Milestones and Complete, respectively. Although in theory V-SOURCE could have helped students make a better college match and thus persist at a higher rate even without increasing first fall enrollment, the effects on persistence (Table 10) are also small and statistically insignificant after adjusting for multiple comparisons.

\footnotetext{
${ }^{30}$ The point estimates suggest that the marginal application converted to at least one acceptance 63 percent of the time for CSU (0.026/0.041) and 30 percent of the time for UC (0.013/0.044). Acceptance rates vary across campus within each system and, of course, depend on students' qualifications, but these acceptance rates are in the range of what one might expect based on acceptance rates in each system (reported in Phillips and Reber (2019)).

${ }^{31}$ We use the NSC matches to construct indicators for the enrollment outcomes for the same categories as applications and acceptances: (1) any four-year college, (2) any selective 4-year college, (3) any CSU, and (4) any UC. The enrollment measure is equal to 1 if a student enrolled in the specified category in the first fall after expected on-time graduation from high school. The measures of persistence are equal to one if a student met the criteria in both the first and second falls after expected on-time high school graduation. For example, the two-year persistence measure for attending a 4-year college is equal to one if the student attended a 4-year college in both the first fall and the second fall, even if it was not the same institution or enrollment was not continuous. Although it is possible that the program induced participants into (or out of) schools that disproportionately report (or don't report) to the NSC, our results based on self-reported data on enrollment plans are similar to those from the NSC, which suggests that this is not an important source of bias.
} 


\section{HETEROGENEOUS EFFECTS}

\subsection{Heterogeneous EFFECTS By DEMographic GrouP}

Based on the results from the SOURCE evaluation, we anticipated that students from Hispanic, Spanishspeaking households and first-generation college-going students would benefit most from V-SOURCE. Prior work by Carrell and Sacerdote (2017) also suggested effects might vary by gender. We targeted recruitment to schools with large populations of students we thought could benefit most, but the study did not enroll such students exclusively. We therefore blocked on these variables in the random assignment and estimate heterogeneous treatment effects by these characteristics. For completeness, we report estimates for all the outcomes presented in Section 5 in Appendix D for each of the three blocking variables; we adjust for multiple hypotheses as described above. The estimates for these subgroup analyses are generally not precise enough to detect statistically significant differences between the treatment effects for different groups, so we discuss the patterns of point estimates across the outcomes and sub-groups with that in mind.

We do not find consistent evidence that women or men benefited more from the program (Tables D.1b to D.1g). Nor do we find consistent evidence that students whose parents did not attend college benefited more from the program, though the estimated effects of the Complete program on college applications are somewhat larger for those students (Tables D.3b to D.3g).

We do find suggestive evidence, however, that the program was more effective for Hispanic students from Spanish-speaking families, the same group for which the predecessor SOURCE program had the largest effects. ${ }^{32}$ The point estimates suggest that students assigned to the Complete program applied more broadly to colleges (Table D.2d) and were more likely to be accepted to a broader range of colleges, particularly to at least one UC (Table D.2e). Students assigned to both variants were also more likely to enroll and persist at a UC campus (Tables D.2f and D.2g), though these effects are not significant after adjusting for multiple hypotheses. The point estimates for two-year persistence of about 3.5 percentage points are modest in absolute terms but large relative to the control mean of 9 percent.

\subsection{AdDitional EXPLORATORY HETEROGENEITY ANALYSES}

We conducted additional sub-group analyses to provide some insight into the mechanisms by which the program operated. We examined 1) the extent to which the effects aligned with what we might anticipate given students' academic qualifications, 2) whether the program was more effective for students whose had fewer alternative sources of support in their families and at school, and 3) whether the program was more effective for students who self-identified as being disorganized or prone to procrastination. We consider these analyses exploratory and generally do not have sufficient to power to draw strong conclusions, so we do not do adjustments for multiple comparisons. We describe how we measured these constructs and report estimates for applications, acceptances, and fall enrollment in Appendix E. We focus this discussion mostly on the college application portfolio, the key intermediate

\footnotetext{
${ }^{32}$ Note, however, that these effects tend to be statistically indistinguishable from the estimates for the other race/language groups.
} 
outcome the program was designed to influence, keeping in mind that changes in applications typically did not translate to changes in college enrollment.

The estimates of heterogeneous treatment effects by pre-program GPA suggest that the Complete program induced additional applications on the appropriate margins given students' academic preparation (Table E.1b); lower-GPA students were more likely to submit a CSU application, moderate GPA students were more likely to submit a UC application, and high GPA students were somewhat more likely to do both. The estimates for Milestones follow a similar pattern but are smaller in magnitude (and statistically insignificant). These results suggest that the program had some success targeting advice based on academic background and that having an advisor, rather than just automated information, may be important for increasing applications.

A key goal of V-SOURCE was to provide assistance with the college access process to students who would otherwise get little support from their parents or at school, so we estimated heterogeneous treatment effects by several baseline measures of expected family and school support for applying to college. The results suggest that V-SOURCE was more helpful to students who did not have other sources of support. Consistent with Carrell and Sacerdote (2017), we found larger effects on college applications among students who reported at baseline that their parents would not help them with college applications if they asked (Table E.2b). ${ }^{33}$ Students who reported that their parents would not help with college applications were quite similar on a broad range of measures-GPA, educational aspirations for themselves, parent and teacher educational expectations for them, being U.S. born, and the self-perception measures related to procrastination/disorganization and hard work-to students who reported that their parents would help them with applications. Not surprisingly, students who reported that their parents would not help them with their applications were more likely to speak Spanish at home and to have parents who were foreign born and had little education (Table E.2a).

Effects on applications are also larger for students who did not report that a teacher and/or counselor would help them with their applications if they asked (Table E.4b). Almost 80 percent of students reported that a teacher and/or counselor would help with applications if they asked; the 20 percent who did not were slightly more likely to describe themselves as procrastinators and less hard working, and reported somewhat lower grades, on average, but not exclusively so (e.g., 36 percent had a GPA of 3.5 or higher; Table E.4a). These results suggest that the larger effects for low GPA students reported above could be related to lower levels of alternative support for those students, though we could not experimentally vary GPA or the availability of other help so cannot say for sure. The effects do not differ based on another measure of school support-whether a student had participated in a college access program at baseline (Table E.5b).

Although we caution that differences across sub-groups are generally not statistically significant and in most cases increased applications did not translate to more enrollments, taken as a whole, the estimates suggest that V-SOURCE Complete helped meet the need of students who did not have other people, particularly parents, who could help them with their college applications. These findings are

\footnotetext{
${ }^{33}$ The question asked, "Thinking of the people in your life, which of the following people... will help you with college applications if you ask?" Response options were not mutually exclusive: parent, sister/brother, other relative, family friend, friend, teacher, school counselor, mentor (from a program). We also examined whether effectiveness varied by whether a sibling could help with college applications (Table E.3b).
} 
consistent with Carrell and Sacerdote (2017), who found that their fairly large treatment effects of an inperson college access program were mainly for students whose parents did not help them fill out their applications. $^{34}$

Unsurprisingly, students from Spanish-speaking backgrounds were more likely to report that their parents would not help them with their applications, compared to other groups (Table D.2a). Unfortunately, if we include both the demographic and parental help interactions in the model at the same time, the estimates are too noisy to be informative; but less availability of parental help among this group is probably part of the explanation for the larger effects for Hispanic students from Spanishspeaking households. Note that students from Spanish-speaking families look similar to other groups on a broad range of other measures related to educational aspirations and school and family support for education (Table D.2a). These other measures indicate that these students' parents support their educational endeavors (over 80 percent expect their child to complete at least a BA, and 60 percent will make sure they turn in their applications) but are less able to help fill out college applications specifically.

Finally, several components of the program-for example, the reminders and Milestone Rewards-were designed specifically to address students' lack of organization and tendency to procrastinate, so we expected the treatment to be more helpful for students who were disorganized or prone to procrastination. Indeed, we found larger treatment effects on the application portfolio for students who scored in the highest third on an index of procrastination and disorganization at baseline (Table E.6b). ${ }^{35}$ Note that the differential effects for students who were disorganized or prone to procrastination were similar in Milestones and Complete, whereas for most other heterogeneity analyses, the effects of Complete tended to be larger. These results suggest that students who were more disorganized and more likely to procrastinate may have particularly benefited from the reminders and rewards for completing the key college application milestones, whereas the advisor was more important for other sub-groups.

Altogether, the exploratory analyses suggest that the program operated as designed-encouraging applications on academically-relevant margins, providing help where parents and schools could not, and encouraging disorganized students to complete key application tasks on time. However, these effects were generally not large enough to translate to increased college enrollments, or students faced additional barriers to enrollment.

\footnotetext{
${ }^{34}$ We examine heterogeneity based on whether students reported that their parent would "help you with college applications if you ask?" Carrell and Sacerdote's (2017) question asked whether a parent had helped with college applications. We asked the question prior to random assignment, whereas the Carrell and Sacerdote (2017) asked the question post random assignment. Their post-treatment measure could reflect crowd-out-substitution of the program for help parents would have otherwise provided-but they argue this was not the case.

${ }^{35}$ We also expected individuals with present-biased preferences to procrastinate (Laibson 1997). We attempted to measure present bias using standard questions eliciting discount rates now, and in the future, but more than half of students gave answers consistent with future-biased preferences, and many responses were internally inconsistent or implied extremely high discount rates. The data suggest that the students did not interpret the questions as expected, and the responses did not measure present bias, so we focus on the items asking about procrastination here.
} 


\section{DisCUSSION: UNDERSTANDING THE NULL ENROLLMENT EFFECTS}

Although theory and past research suggest that providing additional information and support to disadvantaged students during the college and financial aid application process might improve students' college enrollment outcomes, our randomized evaluation found that a program designed to provide such information and support virtually did not increase students' likelihood of enrolling or persisting in a four-year college for the average student who participated in the study. The average effects of the program on intermediate outcomes, such as students' perceptions of support during the college application process and applications to at least one four-year college, indicate that the program affected the mechanisms we thought would lead to improvements in four-year college enrollment. The heterogeneity results also provide support for key hypothesized mechanisms: the program (especially Complete) induced applications on the relevant margins depending on student GPA, had larger effects for students whose families were less able to help with the college application process and had larger effects for students who were disorganized or prone to procrastinate.

In this section, we discuss potential explanations for the null finding on college enrollment and compare our findings to other studies of college access programs, which we summarize in more detail in Appendix A. That summary includes experimental studies of programs that mainly provided assistance in applying to college and/or for financial aid (loosely, "college counseling" programs). We exclude studies of college access programs that focused solely on academic remediation or providing financial aid (rather than help applying for financial aid) and studies of policy changes related to college access (such as financial aid or test-taking policy).

\subsection{SElection into the STUdy And Counterfactual Condition}

The characteristics of our sample and the conditions experienced by the control group may help explain the small effects we found and differences between our results and those of past studies.

Students had to choose to enroll in the study and probably did not apply for V-SOURCE unless they had some sense that they wanted to go to college. Students also had to complete the short application, get a parent's signature, and return it in a pre-addressed stamped envelope (or to school) by a deadline to enroll in the study. Students who were able to complete these tasks on time may have been less in need of the V-SOURCE program, particularly the reminders. Prior studies have found that those who volunteer to participate in a program may not be the ones who benefit most; in fact, the reverse may be true. For example, those most likely to sign up for Head Start (Kline and Walters 2018) and Section 8 housing vouchers (Chyn 2018) tend to benefit least from those interventions. Nathan (2013) found suggestive evidence that Upward Bound, a federally funded college access program, was more effective for those not targeted by the program. By this logic, V-SOURCE might have been more effective if it had not required students to sign up.

We cannot measure selection into the study directly, but we can compare some outcomes in our sample to some benchmark populations. Given that the program was targeted to students who were on track to apply to public four-year colleges, it is not surprising that the four-year college enrollment rate among Los Angeles Unified students in the V-SOURCE control group (43 percent) was higher than for graduates 
in the same cohorts for the whole district (25 and 27 percent for 2013 and 2014, respectively) (Phillips, Yamashiro, and Jacobson 2017). Similarly, 78 percent of the V-SOURCE control group overall and 81 percent of LAUSD students in the control group reported applying to at least one four-year college, compared to 63 percent of a national sample of public high school graduates in 2013 and 64 percent of LAUSD 12th graders in 2017 (Miller, Phillips, and Yamashiro, 2018). We expected the reminder components of the program to be particularly effective for students who tend to procrastinate or be disorganized, conditional on academic achievement. Unfortunately, we cannot determine whether our sample was positively selected on these "non-cognitive" skills, but the fact that effects on the application portfolio were larger for students who are more prone to disorganization and procrastination (Table E.6b) suggests such students could particularly benefit from this type of intervention.

We can also examine the outcomes of the control group to get some insight into how much scope there was for V-SOURCE to improve outcomes. While according to the CSAC-augmented enrollment measures, 81 percent of the control group enrolled in some type of college in the first fall after expected high school graduation, only 52 percent enrolled in a four-year college, leaving 19 percent of students who could have been induced into any college and 29 percent who could have been shifted on the two-yearfour-year margin (the margin on which the intervention was primarily design to operate). ${ }^{36}$ While control students who did not enroll in a four-year college had lower GPAs on average, over 60 percent of this group (35 percent of the whole sample) had a self-reported GPA of 3.0 or better, suggesting they could have been admitted to some CSU or even UC campuses. The control mean for four-year college enrollment is lower in V-SOURCE compared to SOURCE (Bos et al. 2012), suggesting that the V-SOURCE sample is, if anything, less positively selected on counterfactual outcomes. ${ }^{37}$

A major goal of the intervention was to increase the extent to which students completed key steps in the college application process so that they would have four-year college options and not default to enrollment in a two-year college. Students in the control group completed key milestones targeted by the program at high rates -83 percent reported that they took the ACT or SAT, 79 percent completed a FAFSA on time, and 78 percent reported they applied to at least one four-year college. ${ }^{38}$ The high rate of on-time FAFSA completion in the control group is perhaps surprising in light of recent emphasis on FAFSA as a barrier to college enrollment (e.g., Bettinger et al. 2012; Dynarski and Scott-Clayton 2006). The high rates in this sample could be due to the significant simplification of the FAFSA for low-income students, increased emphasis on and support for FAFSA completion in the community, selection into the

\footnotetext{
${ }^{36}$ These figures are more inclusive of college enrollment than the NSC data (Table C.4).

${ }^{37}$ Using comparable measures of four-year enrollment, the four-year enrollment rate in V-SOURCE is about 10 percentage points lower than in SOURCE, though the CSAC-augmented four-year enrollment rate in V-SOURCE matches the SOURCE four-year enrollment almost exactly. We do not know whether the under-matching to NSC data was similar when the SOURCE study was conducted. In any case, it seems the SOURCE and V-SOURCE counterfactual enrollments are at least similar.

${ }^{38}$ Data on SAT/ACT taking and college applications come from the Follow-up Survey, and the sample of survey completers are somewhat positively selected. We were concerned that self-reported FAFSA completion might be particularly unreliable since the process can be confusing and students sometimes mistakenly believe they successfully submitted the form, so we obtained administrative data on FAFSA completion data from CSAC. For the sample who answer the FAFSA question on the Follow-up Survey, the self-reported FAFSA completion rate was 86 percent versus 81 percent in the administrative data; the on-time FAFSA completion rate was 79 percent for the full sample.
} 
study, or some combination of the three. As for college enrollment, the control means for SAT-taking and FAFSA completion are in a similar range to the control means in SOURCE (Bos et al. 2012).

Students in the control group reported reasonably high levels of support, but again, there was room for improvement. On the Follow-up Survey, 59 percent of the control group said they felt "well-informed" or "very well-informed" throughout the college and financial aid application process, and just 44 percent participated in at least one non-V-SOURCE college access program.

Overall, the experience of the control group suggests that a large share of the sample had access to other sources of information and support for college application and completed the key application milestones; about half ultimately enrolled in a four-year college. Still, the outcomes in the counterfactual condition leave scope for an intervention to produce modest improvements. Recall that the intervention was not intensive, and we did not expect large effects on four-year enrollment: We powered the study to detect effects as small as about 4 percentage points for Milestones, and indeed our estimates are sufficiently precise to reject effects in this range.

\subsection{Program Design}

V-SOURCE was designed explicitly to test whether an entirely virtual-and therefore scalable-program could improve college enrollment. We speculate that the virtual nature of V-SOURCE limited its effectiveness. Prior studies in other contexts have shown that in-person advising interventions can be effective, ${ }^{39}$ and the in-person predecessor to V-SOURCE, SOURCE, produced larger effects (Bos et al. 2012) than we find here. Despite some differences in geographic scope (SOURCE was limited to LAUSD) and timing (the SOURCE study took place in 2006-07), SOURCE and V-SOURCE participants were broadly similar (Table C.5). Consistent with the recruitment strategy for the current study, V-SOURCE students were more likely than SOURCE students to report Spanish as their home language and less likely to have at least one parent who attended college; if anything, these differences should have led us to find larger effects in V-SOURCE because those were the groups that most benefited from SOURCE. ${ }^{40}$ In addition, prior studies that have found significant effects for virtual or mail-based interventions targeting fairly high-achieving students who are likely eligible for admission to selective colleges and for whom information, rather than academic preparation, is likely to be the key barrier to enrollment. ${ }^{41}$ Both the Milestones and Complete treatments increased enrollment and persistence in the more-selective UC system among students from Spanish-speaking families, though the effects were fairly small (and insignificant after adjusting for multiple hypotheses). Although we did not directly test the in-person

\footnotetext{
${ }^{39}$ See, for example, Avery (2013), Barr and Castleman (2018), Bettinger and Evans (2019), Bettinger et al. (2013), Carrell and Sacerdote (2017), and Oreopoulos and Ford (2019). Some of these interventions are not only in-person but also more intensive and expensive than V-SOURCE.

${ }^{40} \mathrm{~V}$-SOURCE students had somewhat higher GPAs and somewhat lower educational expectations, but these differences are not that large and may be attributable to differences in the data sources across the studies. The GPA information comes from students' self-reports in V-SOURCE and administrative data in SOURCE, and an extensive literature indicates that self-reported GPAs tend to be higher than administratively-reported GPAs (see, e.g., Rosen, Porter, and Rogers 2017). The SOURCE educational expectations question asked, "How much education do you think you will complete by age 25 ?" In contrast, the V-SOURCE question first asked about educational aspirations ("If there were not barriers, how far in school would you want to go?") and then asked, "As things stand now, how far in school do you think you will actually get?"

${ }^{41}$ See Dynarski et al. (2019) and Hoxby and Turner (2013), though Gurantz et al. (2019) did not find significant effects for an intervention similar to Hoxby and Turner's (2013) ECO.
} 
versus virtual comparison, our results, considered in the context of prior studies, are broadly consistent with the idea that high-achieving students can benefit from information interventions, whereas moderate- and lower-achieving students may need more-intensive or in-person help.

\subsection{ConTEXT AND TARGETING}

Some features of the California context may also have limited the program's effectiveness, particularly when compared to New Hampshire (Carrell and Sacerdote 2017)..$^{42}$ For example, Carrell and Sacerdote (2017) targeted students identified by school counselors as college ready but who had not taken steps to apply by January of their senior year; this approach would not be possible in California because California's public four-year universities would no longer be accepting students. California's application process is also particularly unforgiving - application deadlines are early, and there are no late or open admissions four-year colleges in the state; this may make it more important, but also more difficult, to help students navigate the process. By contrast, New Hampshire (the site of Carrell and Sacerdote's study) and Ohio (the site of the H\&R Block FAFSA study) both have at least one selective four-year college that admits students in the spring. On the other hand, the SOURCE program was more effective in a similar institutional environment, pointing to the virtual nature of the program or the increased availability of alternative sources of information and support, as explanations for the null effects of $\mathrm{V}$ SOURCE on college enrollment.

Ultimately, we cannot say conclusively why our findings differ from studies of related programs, but our analysis suggests that the context and details of college access interventions influence their effectiveness and that many socioeconomically disadvantaged students face barriers to college enrollment that are not easily addressed with a low-cost, fully virtual intervention focused on the college and financial aid application process alone.

This and other recent studies point to potential limitations of low-cost, virtual interventions to increase college enrollment among socioeconomically disadvantaged students, suggesting future efforts to increase college enrollment among this group may need to remove some barriers (for example, by simplifying the application process itself) or provide in-person support. However, some open questions about the viability of fully virtual interventions, or how best to combine virtual and in-person components, remain. For example, although text-messaging interventions involving parents of younger students have been successful (see footnote 4), low-cost college access interventions, including VSOURCE, have not involved parents. And most virtual programs start fairly late in students' high school careers. Perhaps pushing virtual information to students and their parents earlier in students' academic careers about college eligibility, college planning, and financial aid availability might have larger effects than V-SOURCE, which began in the spring of students' junior year and pushed information only to students. Likewise, coordinating pushed information and reminders with school counselors' on-going work with students in schools or with in-person classroom sessions focused on college planning, test preparation, and college application might be more effective than a completely virtual intervention like V-SOURCE.

\footnotetext{
${ }^{42}$ See Phillips and Reber (2019) for a description of the process of applying to college in California compared to other states, including New Hampshire.
} 


\section{CONCLUSION}

This paper reports the results from a random assignment field experiment of two virtual college access interventions targeted to students who were on track to be academically eligible for admission to a public four-year college in California. The interventions were designed to provide information and support during the college and financial aid application process and to help students avoid procrastinating about key deadlines. We use a range of data sources-both administrative and selfreported-to show that the program increased the extent to which students felt they were supported and had access to information when applying to college and that program participation moderately increased the completion of key milestones in the application process. However, increased college applications did not translate to more college acceptances, and the program did not increase college enrollment or persistence on average. We find suggestive evidence that the program was effective at increasing enrollment and persistence at University of California (UC) campuses for Hispanic students from Spanish-speaking families, the same group that benefited most from the predecessor SOURCE program. However, these estimates are modest and not statistically significant after adjusting for multiple comparisons.

While previous studies have suggested that relatively low intensity interventions focused on the college application process can yield large increases in college enrollment, this study suggests that the details of the intervention, context, and population served are important. Descriptive analyses indicate a wide gulf between socioeconomically disadvantaged students' educational aspirations and their educational outcomes, even among relatively high-achieving students. Students almost universally aspire and expect to complete a BA but enroll in four-year colleges at much lower rates. This gap between aspirations and outcomes suggests that there is scope for some intervention to improve four-year enrollment among such students, but the virtual V-SOURCE intervention did not help students overcome these barriers on average, and more intensive interventions will likely be required.

\section{REFERENCES}

Abadie, Alberto, Susan Athey, Guido W. Imbens, and Jeffrey Wooldridge. 2017. When Should You Adjust Standard Errors for Clustering? NBER Working Paper 24003.

Avery, Christopher. 2013. Evaluation of the College Possible Program: Results from a Randomized Controlled Trail. NBER Working Paper 19562.

Avery, Christopher and Thomas Kane. 2004. "Student Perceptions of College Opportunities: The Boston COACH program." Pp. 355-394 in College Choices: The Economics of Where to Go, When to Go, and How to Pay for It, edited by Caroline Hoxby. Chicago, IL: University of Chicago Press.

Bailey, Martha and Susan Dynarski. 2011. "Inequality in Postsecondary Attainment." Pp. 117-132 in Whither Opportunity: Rising inequality, Schools, and Children's Life Chances, edited by G. Duncan and R. Murnane. New York, NY: Russell Sage Foundation.

Barr, Andrew and Benjamin Castleman. 2018. An Engine of Economic Opportunity: Intensive Advising, College Success, and Social Mobility. (http://people.tamu.edu/ abarr/BL shell 66 2018.pdf)

Barrow, Lisa and Ofer Malamud. 2015. "Is College a Worthwhile Investment?" Annual Review of Economics 7:519-55.

Baum, Sandy, Jennifer Ma, and Kathleen Payea. 2013. The Benefits of Higher Education for Individuals and Society. New York, NY: The College Board. 
Becker, Gary S. 1993. Human Capital: A Theoretical and Empirical Analysis with Special Reference to Education (3rd ed.). Chicago, IL: University of Chicago Press.

Benjamini, Yoav and Yosef Hochberg. 1995. "Controlling the False Discovery Rate: A Practical and Powerful Approach to Multiple Testing." Journal of the Royal Statistical Society Series B Methodological, 57(1):289-300.

Bergman, Peter and Eric W. Chan. 2019. "Leveraging Parents through Low-Cost Technology: The Impact of High-Frequency Information on Student Achievement." Journal of Human Resources 11189837R1.

Bergman, Peter, Jeffrey T. Denning, and Dayanand Manoli. 2019. "Is Information Enough? The Effect of Information about Education Tax Benefits on Student Outcomes." Journal of Policy Analysis and Management 38(3):706-31.

Beshears, John, James J. Choi, David Laibson, and Brigitte C. Madrian. 2008. "The Importance of Default Options for Retirement Saving Outcomes: Evidence from the United States." Pp. 59-87 in Lessons from Pension Reform in the Americas, edited by S. J. Kay and T. Sinha. Oxford: Oxford University.

Bettinger, Eric, Bridgette Terry Long, Philip Oreopoulos, and Lisa Sanbonmatsu. 2012. "The Role of Application Assistance and Information in College Decisions: Results from the H\&R Block FAFSA Experiment." The Quarterly Journal of Economics 127(3):1205-1242.

Bettinger, Eric P. and Brent J. Evans. 2019. "College Guidance for All: A Randomized Experiment in PreCollege Advising." Journal of Policy Analysis and Management 38(3):579-99.

Bird, Kelli A., Benjamin L. Castleman, Jeffrey T. Denning, Joshua Goodman, Cait Lamberton, and Kelly Ochs Rosinger. 2019. "Nudging at Scale: Experimental Evidence from FAFSA Completion Campaigns." Annenberg Institute at Brown University Working Paper.

Bloom, Howard S. and Charles Michalopoulos. 2010. When is the Story in the Subgroups? Strategies for Interpreting and Reporting Intervention Effects for Subgroups. MDRC Working Paper.

Bourdieu, Pierre. 1984. Distinction: A Social Critique of the Judgment of Taste. London, U.K.: Routledge.

Bourdieu, Pierre, and Jean-Claude Passeron. 1977. Reproduction in Education, Society, and Culture. Beverly Hills, CA: Sage.

Bos, Johannes M., Jacqueline Berman, Thomas J. Kane, and Fannie M. Tseng. 2012. The Impacts of SOURCE: A Program to Support College Enrollment through Near-Peer, Low-Cost Student Advising. Draft paper presented at the Association for Public Policy and Management annual meeting.

Bozick, Robert and Erich Lauff. 2007. Education Longitudinal Study of 2002 (ELS:2002): A First Look at the Initial Postsecondary Experiences of the Sophomore Class of 2002 (NCES 2008-308). National Center for Education Statistics, Institute of Education Sciences, U.S. Department of Education. Washington, DC.

Buchman, Claudia, Dennis J. Condron, and Vincent J. Rocigno. 2010. "Shadow Education, American Style: Test Preparation, the SAT, and College Enrollment." Social Forces 89(2):435-462.

Cabell, Sonia Q., Tricia A. Zucker, Jamie DeCoster, Stefanie B. Copp, and Susan Landry. 2019. "Impact of a Parent Text Messaging Program on Pre-Kindergarteners' Literacy Development." AERA Open 5(1):233285841983333.

Card, David. 2001. "Estimating the Return to Schooling: Progress on Some Persistent Econometric Problems." Econometrica 69(5):1127-1160.

Carrell, Scott and Bruce Sacerdote. 2017. "Why do College-Going Interventions Work?" American Economic Journal: Applied Economics 9(3):124-151.

Castleman, Benjamin L., Lindsay C. Page, and Korynn Schooley. 2014. "The Forgotten Summer: Does the Offer of College Counseling After High School Mitigate Summer Melt among College-Intending, 
Low-Income High School Graduates?" Journal of Policy Analysis and Management 33(2):320344.

Castleman, Benjamin L. and Lindsay C. Page. 2014. Summer Melt: Supporting Low-Income Students Through the Transition to College. Cambridge, MA: Harvard Education Press.

Chyn, Eric. 2018. "Moved to Opportunity: The Long-Run Effects of Public Housing Demolition on Children." American Economic Review 108(10): 3028-3056.

Coleman, James S. 1988. "Social Capital in the Creation of Human Capital." American Journal of Sociology 9(4):95-120.

Dynarski, Susan, C. J. Libassi, Katherine Michelmore, and Stephanie Owen. 2018. Closing the Gap: The Effect of a Targeted, Tuition-Free Promise on College Choices of High-Achieving, Low-Income Students. NBER Working Paper 25349.

Dynarski, Susan M. and Judith Scott-Clayton. 2006. "The Cost of Complexity in Student Financial Aid: Lessons from Optimal Tax Theory and Behavioral Economics." National Tax Journal 59(2):319356.

Dynarski, Susan M. and Judith Scott-Clayton. Spring, 2013. "Financial Aid Policy: Lessons from Research." Future of Children 23(1):67-91.

Dynarski, Susan M., Steven W. Hemelt, and Joshua M. Hyman. 2013. The Missing Manual: Using National Student Clearinghouse Data to Track Postsecondary Outcomes. NBER Working Paper \#19552.

Ellwood, David and Thomas Kane. 2000. "Who is Getting a College Education? Family Background and the Growing Gaps in Enrollment." Pp. 283-324 in Securing the Future, edited by S. Danziger and J. Waldfogel. New York, NY: Russell Sage Foundation.

French, Robert and Philip Oreopoulos. 2017. "Applying Behavioural Economics to Public Policy in Canada." Canadian Journal of Economics 50(3):599-635.

Fryer, Jr. Roland G. 2016. "Information, Non-Financial Incentives, and Student Achievement: Evidence from a Text Messaging Experiment." Journal of Public Economics 144:109-21.

Grodsky, Eric and Catherine Riegle-Crumb. 2010. "Those Who Choose and Those Who Don't. Social Background and College Orientation." Annals of the American Academy of Political and Social Science 627:14-35.

Grodsky, Eric and Melanie T. Jones. 2007. "Real and Imagined Barriers to College Entry: Perceptions of Cost." Social Science Research 36:745-766.

Gurantz, Oded, Jessica Howell, Mike Hurwitz, Cassandra Larson, Matea Pender, and Brooke White. 2019. "Realizing Your College Potential? Impacts of College Board's RYCP Campaign on Postsecondary Enrollment." Annenberg Institute at Brown University Working Paper.

Horvat, Erin M. 2001. "Understanding Equity and Access in Higher Education: The Potential Contribution of Pierre Bourdieu." Pp. 158-171 in Higher Education: Handbook of Theory and Research, edited by J.C. Smart. New York, NY: Agathon Press.

Hout, Michael. 2012. "Social and Economic Returns to College Education in the United States." Annual Review of Sociology 38:379-400.

Hoxby, Caroline and Sarah Turner. 2013. Expanding College Opportunities for High-Achieving, Low Income Students. Stanford Institute for Economic Policy Research Discussion Paper 12-014.

Ingels, Steven J., and Ben Dalton. 2013. High School Longitudinal Study of 2009 (HSLS:09) First Followup: A First Look at Fall 2009 Ninth Graders in 2012 (NCES 2014-360). U.S. Department of Education. Washington, DC: National Center for Education Statistics.

Jacob, Brian A. and Tamara Wilder Linkow. 2011. "Educational Expectations and Attainment." Pp. 133162 in Whither Opportunity?: Rising Inequality, Schools, and Children's Life Changes, edited by Greg J. Duncan, and Richard J. Murnane. New York, NY: Russell Sage.

Klasik, Daniel. 2012. "The College Application Gauntlet: A Systematic Analysis of the Steps to Four-Year College Enrollment." Research in Higher Education 53:506-549. 
Kling Jeffrey R, Jeffrey B Liebman and Lawrence F Katz. 2007. "Experimental Analysis of Neighborhood Effects." Econometrica 75(1):83-119.

Kraft, Matthew A. and Shaun M. Dougherty. 2013. "The Effect of Teacher-Family Communication on Student Engagement: Evidence from a Randomized Field Experiment." Journal of Research on Educational Effectiveness 6(3):199-222.

Laibson, David. 1997. "Golden Eggs and Hyperbolic Discounting." Quarterly Journal of Economics 112(2):443-477.

Lareau, Annette, and Elliot Weininger. 2008. Class and the Transition to Adulthood. Pp. 118-151 in Social Class: How Does it Work?, edited by A. Lareau and D. Conley. New York, NY: Russell Sage.

Madrian, Brigitte and Dennis F. Shea. 2001. "The Power of Suggestion: Inertia in 401(k) Participation and Savings Behavior." Quarterly Journal of Economics 116(4):1149-118.

Marx, Benjamin M. and Lesley J. Turner. 2019. "Student Loan Nudges: Experimental Evidence on Borrowing and Educational Attainment." American Economic Journal: Economic Policy 11(2):108-41.

Mayer, Susan E., Ariel Kalil, Philip Oreopoulos, and Sebastian Gallegos. 2018. "Using Behavioral Insights to Increase Parental Engagement: The Parents and Children Together Intervention." Journal of Human Resources 0617-8835R.

McDonough, Patricia M. 1997. Choosing Colleges. How Social Class and Schools Structure Opportunity. Albany, NY: State University of New York.

McDonough, Patricia M. 2004. “Counseling Matters: Knowledge, Assistance, and Organizational Commitment in College Preparation." Pp. 69-87 in Preparing for College: Nine Elements of Effective Outreach, edited by W.G. Tierney, Z.B. Corwin, and J.E. Colyar. Albany, NY: SUNY Press.

Miller, Carrie E., Phillips, Meredith, and Kyo Yamashiro. 2018. L.A. Unified Students' pathways to College: Four-Year College Application Patterns. Research Brief. Los Angeles Education Research Institute.

Nathan, Alan. 2013. Does Upward Bound Have an Effect on Student Educational Outcomes? A Reanalysis of the Horizons Randomized Controlled Trial Study. Dissertation, University of Wisconsin, Madison.

National Student Clearinghouse Research Center. 2014. Using NSC StudentTracker for High School Reports: Considerations for Measuring the College Enrollment Rates of High School Graduates. Herndon, VA. (https://nscresearchcenter.org/wp-content/uploads/Considerations-in-Using-NSCSTHS-Reports.pdf)

Olson, Lorayn and Rachel A. Rosenfeld. 1984. "Parents and the Process of Gaining Access to Student Financial Aid." The Journal of Higher Education 55(4):455-480.

Oreopoulos, Philip and Reuben Ford. 2019. "Keeping College Options Open: A Field Experiment to Help All High School Seniors through the College Application Process: Keeping College Options Open." Journal of Policy Analysis and Management 38(2):426-54.

Oreopolos, Philip and Uros Petronijevic. 2013. "Making College Worth It: A Review of the Returns to Higher Education." The Future of Children 23(1):41-65.

Oreopoulos, Philip and Uros Petronijevic. 2018. "Student Coaching: How Far Can Technology Go?" Journal of Human Resource 53(2):299-329.

Orne, Martin T. 1962. "On the Social Psychology of the Psychological Experiment: With Particular Reference to Demand Characteristics and Their Implications." American Psychologist 17(11):776-83.

Page, Lindsay C. and Judith Scott-Clayton. 2016. "Improving College Access in the United States: Barriers and Policy Responses." Economics of Education Review 51:4-22. 
Perna, Laura W. 2006. Studying College Access and Choice: A Proposed Conceptual Model. In Higher Education: Handbook of theory and Research, edited by J. Smart and M. Paulsen, 99-157. Memphis, TN: Springer.

Perna, Laura W. 2008. 'Understanding High School Students' Willingness to Borrow to Pay College Prices." Research in Higher Education 49:589-606.

Phillips, Meredith. 2011. "Ethnic and Social Class Disparities in Academic Skills: Their Origins and Consequences." Pp. 7-24 in Diversity in American Higher Education: Toward a More Comprehensive Approach, edited by L.M. Stulberg, and S.L. Weinberg. New York, NY: Routledge.

Phillips, Meredith and Sarah Reber. 2019. Report on the Implementation and Impacts of the V-SOURCE College Access Program. (Available at https://www.sarahreber.com/vsource)

Phillips, Meredith, Kyo Yamashiro, and Thomas A. Jacobson. 2017. College Going in LAUSD: An Analysis of College Enrollment, Persistence, and Completion Patterns. Research Report. Los Angeles Education Research Institute.

Plank, Stephen B. and Will J. Jordan. 2001. "Effects of Information, Guidance, and Actions on Postsecondary Destinations: A Study of Talent Loss." American Educational Research Journal 38(4):947-979.

Robinson, Carly D., Monica G. Lee, Eric Dearing, and Todd Rogers. 2018. "Reducing Student Absenteeism in the Early Grades by Targeting Parental Beliefs." American Educational Research Journal 55(6):1163-92.

Robinson, Karen Jeong, and Josipa Roksa. 2016. "Counselors, Information, and High School CollegeGoing Culture: Inequalities in the College Application Process." Research in Higher Education 57:845-868.

Roderick, Melissa, Vanessa Coca, and Jenny Nagaoka. 2011. "Potholes on the Road to College: High School Effects in Shaping Urban Students' Participation in College Application, Four-year College Enrollment, and College Match." Sociology of Education 84(3):178-211.

Rogers, Todd and Avi Feller. 2018. "Reducing Student Absences at Scale by Targeting Parents' Misbeliefs." Nature Human Behaviour 2(5):335-42.

Rosen, Jeffrey A., Stephen R. Porter, and Jim Rogers. 2017. "Understanding Student Self-Reports of Academic Performance and Course-Taking Behavior." AERA Open 3(2):1-14.Rouse, Cecelia Elena. 2004. "Low-Income Students and College Attendance: An Exploration of Income Expectations." Social Science Quarterly 85:1299- 1317.

Schochet, Peter Z. 2008. Technical Methods Report: Guidelines for Multiple Testing in Impact Evaluations. National Center for Education Evaluation and Regional Assistance, Institute of Education Sciences.

Sewell, William H. and Robert M. Hauser. 1972. "Causes and Consequences of Higher Education: Models of the Status Attainment Process." American Journal of Agricultural Economics 54(5):851-861.

Steinberg, Laurence, Sandra Graham, Lia O'Brien, Jennifer Woolard, Elizabeth Cauffman, and Marie Banich. 2009. "Age Differences in Future Orientation and Delay Discounting." Child Development 80(1):28-44.

Stephan, Jennifer and James E. Rosenbaum. 2013. "Can High Schools Reduce College Enrollment Gaps With a New Counseling Model?" Educational Evaluation and Policy Analysis 35(2):200-219.

Webb, Eugene J., Donald T. Campbell, Richard D. Schwartz, and Lee Sechrest. 1966. Unobtrusive Measures. Chicago, IL: Rand McNally.

York, Benjamin N., Susanna Loeb, and Christopher Doss. 2019. "One Step at a Time: The Effects of an Early Literacy Text-Messaging Program for Parents of Preschoolers." Journal of Human Resources, 54(3):537-566.

Zizzo, Daniel John. 2010. "Experimenter Demand Effects in Economic Experiments." Experimental Economics 13(1):75-98. 
Table 1. V-SOURCE Program Components

\begin{tabular}{|c|c|c|}
\hline SAT/ACT & Milestones & Complete \\
\hline Automated email and text deadline reminders about SAT registration & $\mathrm{X}$ & $X$ \\
\hline Automated email and text deadline reminders about SAT test deadlines & $\mathrm{X}$ & $\mathrm{X}$ \\
\hline$\$ 20$ gift card for registering for SAT or ACT & $\mathrm{X}$ & $\mathrm{X}$ \\
\hline$\$ 20$ gift card for taking SAT or ACT & $\mathrm{X}$ & $\mathrm{X}$ \\
\hline Automated email and text information and encouragement about the SAT/ACT & $\mathrm{X}$ & $\mathrm{X}$ \\
\hline Automated email and text references/links to SAT prep on V-SOURCE website & $\mathrm{X}$ & $\mathrm{X}$ \\
\hline $\begin{array}{l}\text { Web-based 12-week SAT curriculum developed specifically for students scoring below } \\
\text { national median }\end{array}$ & $\mathrm{X}$ & $\mathrm{X}$ \\
\hline $\begin{array}{l}\text { Personalized V-Track pages on the website where students could track their SAT prep } \\
\text { progress and view completed prep, scores, and additional prep, including review quizzes that } \\
\text { directed students to lessons they needed. }\end{array}$ & $X$ & $\mathrm{X}$ \\
\hline $\begin{array}{l}\text { Website information about the SAT/ACT, including step-by-step instructions on how to } \\
\text { register }\end{array}$ & $\mathrm{X}$ & $\mathrm{X}$ \\
\hline Provision of SAT fee waivers for qualifying students & $\mathrm{X}$ & $\mathrm{X}$ \\
\hline Personalized advice and help from advisor with registering for SAT/ACT & & $\mathrm{X}$ \\
\hline Personalized advice and help from advisor with preparing for the SAT & & $\mathrm{X}$ \\
\hline \multicolumn{3}{|l|}{ College Application } \\
\hline Automated email and text reminders about upcoming college application deadlines & $\mathrm{X}$ & $\mathrm{X}$ \\
\hline$\$ 20$ gift card for applying to two four-year college systems (e.g., UC and CSU) & $\mathrm{X}$ & $X$ \\
\hline Interactive, month-by-month checklists of tasks to stay on track for college admission & $\mathrm{X}$ & $\mathrm{X}$ \\
\hline $\begin{array}{l}\text { Personalized V-Track pages on the website where students could track their personal } \\
\text { progress through interactive college application materials and worksheets (building "apply } \\
\text { to" lists, creating essays, writing resumes, etc.) }\end{array}$ & $\mathrm{X}$ & $\mathrm{X}$ \\
\hline Automated email and text information and encouragement related to college applications & $\mathrm{X}$ & $X$ \\
\hline $\begin{array}{l}\text { Access to website that addresses common college application/attendance obstacles; } \\
\text { describes types of colleges and suggestions about how to make an "apply to" list; provides } \\
\text { worksheets so students can review their classes and grades and figure out the best way to } \\
\text { meet CSU and UC course eligibility requirements (known as the A-G requirements); provides } \\
\text { brainstorming exercises for essays, with results emailed back to the user; describes how to } \\
\text { create information packets to give to recommendation letter writers; offers step-by-step } \\
\text { instructions on how to fill out online college applications }\end{array}$ & $\mathrm{X}$ & $\mathrm{X}$ \\
\hline $\begin{array}{l}\text { Monitored "comment" sections on all web pages where students could ask specific } \\
\text { questions }\end{array}$ & $\mathrm{X}$ & $\mathrm{X}$ \\
\hline $\begin{array}{l}\text { Personalized advice and help from advisor with compiling college "apply to" lists, } \\
\text { brainstorming and proofreading essays, compiling "brag sheets" and resumes, answering } \\
\text { parents' questions, finding and completing applications, choosing among college } \\
\text { acceptances }\end{array}$ & & $\mathrm{X}$ \\
\hline
\end{tabular}


Table 1 (cont). V-SOURCE Program Components

\begin{tabular}{|c|c|c|}
\hline Financial Aid Application & & \\
\hline Automated email and text reminders about upcoming financial aid application deadlines & $\mathrm{X}$ & $\mathrm{X}$ \\
\hline$\$ 20$ gift card for submitting the FAFSA by the CalGrant deadline & $\mathrm{X}$ & $\mathrm{X}$ \\
\hline $\begin{array}{l}\text { Automated email and text information and encouragement related to applying for financial } \\
\text { aid }\end{array}$ & $\mathrm{X}$ & $\mathrm{x}$ \\
\hline Regular email and text information about upcoming scholarship deadlines & $\mathrm{X}$ & $\mathrm{X}$ \\
\hline $\begin{array}{l}\text { Website pages containing lists of scholarships with abstracts and links, organized by student } \\
\text { grade, citizenship status, and other demographics }\end{array}$ & $\mathrm{X}$ & $\mathrm{x}$ \\
\hline $\begin{array}{l}\text { Detailed online slideshows that walked students and parents through each page and section } \\
\text { of the FAFSA, Dream Act Application, and CSS Profile, describing what students and parents } \\
\text { should enter in different areas, ways to solve common problems (e.g., what to do if parents } \\
\text { do not have social security numbers), what assets to report (e.g., not the family home, small } \\
\text { family business), and advice on how to deal with larger issues (e.g., parents who will not } \\
\text { provide financial information). }\end{array}$ & $\mathrm{X}$ & $\mathrm{X}$ \\
\hline $\begin{array}{l}\text { Website containing information on who qualifies for financial aid, different types of grants } \\
\text { and loans, how to check Cal Grant status, why students should apply for scholarships, how } \\
\text { work study works, how to read financial aid offers, how to interpret financial aid offers, } \\
\text { common financial aid traps to avoid }\end{array}$ & $\mathrm{X}$ & $\mathrm{X}$ \\
\hline $\begin{array}{l}\text { Information to help students and parents find free/affordable tax preparation so that they } \\
\text { could complete their taxes and complete their financial aid documents }\end{array}$ & $\mathrm{X}$ & $\mathrm{X}$ \\
\hline $\begin{array}{l}\text { Personalized advice and help from advisor with the financial aid application process, } \\
\text { communicating with parents, finding scholarships that fit the student, and choosing among } \\
\text { financial aid offers }\end{array}$ & & $\mathrm{X}$ \\
\hline
\end{tabular}


Table 2. Average Program Use and Perceived Helpfulness of Program Components

\begin{tabular}{|c|c|c|c|}
\hline & Milestones & Complete & Total \\
\hline \multicolumn{4}{|l|}{ Administrative Data } \\
\hline Percent any confirmed contact & 91.6 & 99.0 & 94.4 \\
\hline Percent active after intro & 71.8 & 96.5 & 81.1 \\
\hline Percent interacted $\mathrm{w} /$ advisor after intro & 0.0 & 95.5 & 36.1 \\
\hline Automated emails (monthly average) & 4.0 & 4.1 & 4.0 \\
\hline Automated text messages (monthly average) & 3.6 & 3.5 & 3.5 \\
\hline Total unique days visited website & 5.6 & 8.3 & 6.6 \\
\hline Total unique days visited SAT pages & 2.7 & 3.5 & 3.0 \\
\hline Total rewards claimed & 1.4 & 1.8 & 1.6 \\
\hline Message conversations w/ advisor & 0.0 & 10.8 & 4.1 \\
\hline Phone conversations w/advisor & 0.0 & 1.7 & 0.6 \\
\hline Group emails from advisor & 0.0 & 50.4 & 19.1 \\
\hline Individual emails from advisor & 0.0 & 8.1 & 3.1 \\
\hline Emails sent to advisor & 0.0 & 7.6 & 2.9 \\
\hline Total two-way interactions w/ advisor & 0.0 & 20.1 & 7.6 \\
\hline $\mathrm{N}$ & 2553 & 1551 & 4104 \\
\hline \multicolumn{4}{|l|}{$\begin{array}{l}\text { Percent reporting ... at least a few times a } \\
\text { month }\end{array}$} \\
\hline Received text message from V-SOURCE & 68.4 & 77.7 & 71.9 \\
\hline Received email from V-SOURCE & 87.7 & 93.2 & 89.8 \\
\hline Visited the V-SOURCE website & 57.8 & 58.8 & 58.2 \\
\hline Read V-SOURCE Facebook or Twitter & 26.9 & 47.8 & 34.7 \\
\hline Received phone call from V-SOURCE & 24.6 & 41.6 & 31.0 \\
\hline Sent email to V-SOURCE & 25.9 & 55.0 & 36.8 \\
\hline Sent text message to V-SOURCE & 19.7 & 48.2 & 30.3 \\
\hline Posted on V-SOURCE Facebook & 16.3 & 25.2 & 19.6 \\
\hline Called V-SOURCE & 15.4 & 23.2 & 18.3 \\
\hline $\mathrm{N}$ & 2021 & 1208 & 3229 \\
\hline \multicolumn{4}{|l|}{$\begin{array}{l}\text { Percent reporting found ... program } \\
\text { component helpful or very helpful }\end{array}$} \\
\hline V-SOURCE website & 76.8 & 75.9 & 76.5 \\
\hline Text messages & 68.5 & 72.2 & 69.9 \\
\hline Emails & 82.8 & 84.0 & 83.2 \\
\hline Gift card rewards & 87.2 & 87.1 & 87.2 \\
\hline Facebook page & 32.3 & 51.5 & 39.5 \\
\hline Twitter & 27.6 & 28.5 & 28.0 \\
\hline Advisor (Complete only) & 0.0 & 86.3 & 32.3 \\
\hline $\mathrm{N}$ & 2123 & 1272 & 3395 \\
\hline
\end{tabular}

Authors' tabulations of administrative data collected by the V-SOURCE program and self-reported data from Follow-up Survey. 
Table 3. Characteristics of V-SOURCE Research Participants

\begin{tabular}{|c|c|c|c|}
\hline & Cohort 1 & Cohort 2 & Total \\
\hline \multicolumn{4}{|l|}{ Gender } \\
\hline Female & 0.674 & 0.691 & 0.684 \\
\hline $\mathrm{N}$ & 2705 & 3935 & 6640 \\
\hline \multicolumn{4}{|l|}{ Subsidized Lunch Status } \\
\hline Uses Lunch Tickets & 0.609 & 0.496 & 0.537 \\
\hline $\mathrm{N}$ & 2056 & 3672 & 5728 \\
\hline \multicolumn{4}{|l|}{ Race/Ethnicity and Language } \\
\hline Hisp, Sp in Home & 0.526 & 0.512 & 0.518 \\
\hline Hisp, Oth Lang & 0.208 & 0.260 & 0.239 \\
\hline White, $\mathrm{NH}$ & 0.042 & 0.048 & 0.046 \\
\hline Black, NH & 0.070 & 0.054 & 0.060 \\
\hline Asian/PI, NH & 0.125 & 0.099 & 0.109 \\
\hline Other $\mathrm{NH}$ or Missing & 0.030 & 0.026 & 0.028 \\
\hline $\mathrm{N}$ & 2705 & 3935 & 6640 \\
\hline \multicolumn{4}{|l|}{ Parental Education } \\
\hline Missing/DK & 0.041 & 0.025 & 0.032 \\
\hline Less than HS & 0.400 & 0.389 & 0.393 \\
\hline High School (incl Vocational) & 0.189 & 0.205 & 0.198 \\
\hline Some College & 0.220 & 0.234 & 0.229 \\
\hline Four-Year College or More & 0.150 & 0.147 & 0.148 \\
\hline $\mathrm{N}$ & 2705 & 3935 & 6640 \\
\hline \multicolumn{4}{|l|}{ GPA } \\
\hline Less than 2.0 & 0.012 & 0.009 & 0.010 \\
\hline 2 to 2.99 & 0.248 & 0.236 & 0.241 \\
\hline 3 to 3.49 & 0.330 & 0.315 & 0.321 \\
\hline $3.5+$ & 0.411 & 0.441 & 0.429 \\
\hline $\mathrm{N}$ & 2618 & 3843 & 6461 \\
\hline \multicolumn{4}{|l|}{ Educational Aspirations } \\
\hline Less than BA & 0.038 & 0.042 & 0.040 \\
\hline $\mathrm{BA}$ & 0.151 & 0.173 & 0.165 \\
\hline Masters & 0.261 & 0.251 & 0.255 \\
\hline PhD, MD, JD, etc & 0.550 & 0.534 & 0.540 \\
\hline $\mathrm{N}$ & 1942 & 3629 & 5571 \\
\hline \multicolumn{4}{|l|}{ Immigration Status } \\
\hline US Born & 0.823 & 0.849 & 0.840 \\
\hline US Born Parent & 0.243 & 0.295 & 0.276 \\
\hline $\mathrm{N}$ & 2095 & 3685 & 5780 \\
\hline Number of Schools & 59 & 80 & 84 \\
\hline $\mathrm{N}$ & 2705 & 3935 & 6640 \\
\hline
\end{tabular}

Authors' tabulations of analysis sample from Application and Baseline Surveys. All reported data were collected prior to random assignment. Response rate for the Application Survey was near $100 \%$. Response rate for Baseline Survey was $87 \%$ (cohort 1:77\%; cohort 2:94\%). Free lunch status is based on self-reported use of 'lunch tickets.' Respondents checking 'Hispanic' are coded as Hispanic regardless of other race/ethnicity variables checked; otherwise, respondents who checked more than one race-ethnicity are included in the 'Other' category. 
Table 4. Self-Reported Pre-Program Use of Technology among V-SOURCE Research Participants, by Parental Education

\begin{tabular}{|c|c|c|c|c|c|}
\hline & Total & $\begin{array}{c}\text { Less than } \\
\text { High } \\
\text { School }\end{array}$ & $\begin{array}{l}\text { High } \\
\text { School }\end{array}$ & $\begin{array}{l}\text { Some } \\
\text { College }\end{array}$ & $\begin{array}{c}\text { Four-Year } \\
\text { College or } \\
\text { More }\end{array}$ \\
\hline \multicolumn{6}{|l|}{$\begin{array}{l}\text { Use the internet at least a few } \\
\text { times a week by... }\end{array}$} \\
\hline Phone & 0.627 & 0.632 & 0.628 & 0.649 & 0.596 \\
\hline Own Computer & 0.809 & 0.781 & 0.812 & 0.802 & 0.899 \\
\hline At School & 0.306 & 0.311 & 0.300 & 0.300 & 0.312 \\
\hline At a Friend's & 0.074 & 0.069 & 0.070 & 0.071 & 0.088 \\
\hline At the Library & 0.084 & 0.091 & 0.076 & 0.080 & 0.089 \\
\hline Any Method & 0.965 & 0.956 & 0.967 & 0.973 & 0.980 \\
\hline $\mathrm{N}$ & 6609 & 2598 & 1315 & 1511 & 980 \\
\hline \multicolumn{6}{|l|}{ Check email... } \\
\hline At least a few times a week & 0.805 & 0.788 & 0.809 & 0.808 & 0.841 \\
\hline At least a few times a month & 0.957 & 0.943 & 0.965 & 0.965 & 0.974 \\
\hline $\mathrm{N}$ & 6580 & 2583 & 1307 & 1502 & 983 \\
\hline \multicolumn{6}{|l|}{ Text Message... } \\
\hline At least a few times a week & 0.830 & 0.801 & 0.854 & 0.849 & 0.864 \\
\hline At least a few times a month & 0.849 & 0.824 & 0.866 & 0.867 & 0.884 \\
\hline$N$ & 6574 & 2590 & 1298 & 1504 & 975 \\
\hline
\end{tabular}


Table 5. Effects of Assignment to V-SOURCE on Self-Reported Experiences Applying to College and for Financial Aid: Main Experience and Support Constructs

\begin{tabular}{lccc}
\hline & $(1)$ & $(2)$ & $(3)$ \\
& Sought Information & Had Information & Had Support \\
\hline Milestones & -0.033 & $0.086^{* *+}$ & $0.080^{* *+}$ \\
& $(0.027)$ & $(0.026)$ & $(0.026)$ \\
Complete & & & \\
& 0.017 & $0.109^{* *+}$ & $0.152^{* * *+}$ \\
\hline Observations & $(0.031)$ & $(0.030)$ & $(0.027)$ \\
Control Mean & 5,986 & 5,993 & 5,931 \\
\hline
\end{tabular}

Outcomes come from the Follow-up Survey. We standardized each outcome to have mean of 0 and standard deviation of 1 in the control group. Regression includes controls for blocking group indicators, as well as linear, squared, and cubed terms for two GPA measures; for missing values, we impute the mean and include a missing value indicator. Standard errors, clustered on school, are reported in parentheses.

+ Statistically significant at the $5 \%$ level after adjustment for multiple comparisons.

${ }^{*} p<.05,{ }^{* *} p<.01,{ }^{* * *} p<.001$

Table 6. Effects of Assignment to V-SOURCE on Self-Reported Milestone Completion

\begin{tabular}{lcccc}
\hline & $\begin{array}{c}(1) \\
\text { Registered } \\
\text { SAT/ACT }\end{array}$ & $\begin{array}{c}(2) \\
\text { Took SAT/ACT }\end{array}$ & $\begin{array}{c}(3) \\
\text { Applied 2 } \\
\text { systems }\end{array}$ & $\begin{array}{c}(4) \\
\text { Submitted } \\
\text { FAFSA on Time }\end{array}$ \\
\hline Milestones & 0.018 & 0.017 & 0.006 & $0.028^{*}$ \\
& $(0.011)$ & $(0.011)$ & $(0.013)$ & $(0.011)$ \\
Complete & & & & \\
& $0.024^{*}$ & $0.024^{*}$ & $0.054^{* * *+}$ & 0.017 \\
\hline Observations & $(0.011)$ & $(0.010)$ & $(0.013)$ & $(0.012)$ \\
Control Mean & 6,045 & 6,043 & 5,986 & 6,640 \\
\hline ACT/SAT & 0.842 & 0.829 & 0.489 & 0.789 \\
\hline
\end{tabular}

ACT/SAT and application data come from Follow-up Survey; on-time FAFSA submission is based on administrative data from the California Student Aid Commission (CSAC). These are the college-related tasks for which V-SOURCE students could receive Milestones Rewards. Regression includes controls for blocking group indicators, as well as linear, squared, and cubed terms for two GPA measures; for missing values, we impute the mean and include a missing value indicator. Standard errors, clustered on school, are reported in parentheses.

+ Statistically significant at the $5 \%$ level after adjustment for multiple comparisons.

${ }^{*} p<.05,{ }^{* *} p<.01,{ }^{* * *} p<.001$ 
Table 7. Effects of Assignment to V-SOURCE on Self-Reported College Application Outcomes

(1)

Any 4-Year

Milestones

$0.025^{*+}$
Any Selective

(0.010)

$$
0.034^{* *+}
$$

(0.011)

5,986

0.779

0.476

0.476
(2)

(3)

Any CSU

$0.024^{*+}$

(0.011)

(0.012)

$0.036^{* *+}$

(0.013)
$0.041^{* *+}$

(0.013)
(4)

Any UC

0.009

5,986

0.727
$0.044^{* * *+}$

(0.012)
5,986

Control Mean

Outcomes come from the Follow-up Survey. Selective colleges are those with Barron's ratings of very competitive plus to most competitive. Regression includes controls for blocking group indicators, as well as linear, squared, and cubed terms for two GPA measures; for missing values, we impute the mean and include a missing value indicator. Standard errors, clustered on school, are reported in parentheses.

† Statistically significant at the $5 \%$ level after adjustment for multiple comparisons.

${ }^{*} p<.05,{ }^{* *} p<.01,{ }^{* * *} p<.001$

Table 8. Effects of Assignment to V-SOURCE on Self-Reported College Acceptance Outcomes

\begin{tabular}{|c|c|c|c|c|}
\hline & $\begin{array}{c}\text { (1) } \\
\text { Any 4-Year }\end{array}$ & $\begin{array}{c}(2) \\
\text { Any Selective } \\
\end{array}$ & $\begin{array}{c}\text { (3) } \\
\text { Any CSU }\end{array}$ & $\begin{array}{c}\text { (4) } \\
\text { Any UC }\end{array}$ \\
\hline Milestones & $\begin{array}{c}0.000 \\
(0.011)\end{array}$ & $\begin{array}{l}0.005 \\
(0.011)\end{array}$ & $\begin{array}{c}0.004 \\
(0.013)\end{array}$ & $\begin{array}{c}0.010 \\
(0.010)\end{array}$ \\
\hline Complete & $\begin{array}{c}0.017 \\
(0.013) \\
\end{array}$ & $\begin{array}{c}0.008 \\
(0.011) \\
\end{array}$ & $\begin{array}{c}0.026 \\
(0.014) \\
\end{array}$ & $\begin{array}{c}0.013 \\
(0.010) \\
\end{array}$ \\
\hline Observations & 5,986 & 5,986 & 5,986 & 5,986 \\
\hline Control Mean & 0.673 & 0.234 & 0.616 & 0.295 \\
\hline $\begin{array}{l}\text { Outcomes come fro } \\
\text { competitive. Regres } \\
\text { measures; for missi } \\
\text { are reported in pare } \\
+ \text { Statistically signifi } \\
{ }^{*} p<.05,{ }^{* *} p<.01,\end{array}$ & $\begin{array}{l}\text { Survey. Select } \\
\text { trols for block } \\
\text { ute the mean } \\
\text { elel after adjus }\end{array}$ & $\begin{array}{l}\text { ges are those wit } \\
\text { up indicators, as } \\
\text { lude a missing va } \\
\text { or multiple compa }\end{array}$ & $\begin{array}{l}\text { 's ratings o } \\
\text { lear, square } \\
\text { ator. Stand }\end{array}$ & $\begin{array}{l}\text { titive plus } t \\
\text { terms for } \\
\text { ustered on }\end{array}$ \\
\hline
\end{tabular}


Table 9. Effects of Assignment to V-SOURCE on College Enrollment Outcomes

\begin{tabular}{lccccc}
\hline & $\begin{array}{c}(1) \\
\text { Any College }\end{array}$ & $\begin{array}{c}(2) \\
\text { Any 4-Year }\end{array}$ & $\begin{array}{c}(3) \\
\text { Any Selective }\end{array}$ & $\begin{array}{c}(4) \\
\text { Any CSU }\end{array}$ & $\begin{array}{c}(5) \\
\text { Any UC }\end{array}$ \\
\hline Milestones & 0.005 & 0.003 & 0.016 & -0.013 & $0.016^{*}$ \\
& $(0.013)$ & $(0.012)$ & $(0.008)$ & $(0.011)$ & $(0.008)$ \\
Complete & & & & & \\
& 0.006 & 0.007 & 0.001 & 0.003 & 0.005 \\
\hline Observations & $(0.013)$ & $(0.013)$ & $(0.009)$ & $(0.012)$ & $(0.009)$ \\
Control Mean & 6,640 & 6,640 & 6,640 & 6,640 & 6,640 \\
\hline
\end{tabular}

Outcomes come from the National Student Clearinghouse (NSC). College enrollment reflects any enrollment in the fall (September 1 to December 31) following on-time high school graduation. Selective colleges are those with Barron's ratings of very competitive plus to most competitive. Regression includes controls for blocking group indicators, as well as linear, squared, and cubed terms for two GPA measures; for missing values, we impute the mean and include a missing value indicator. Standard errors, clustered on school, are reported in parentheses.

† Statistically significant at the $5 \%$ level after adjustment for multiple comparisons.

${ }^{*} p<.05,{ }^{* *} p<.01,{ }^{* * *} p<.001$

Table 10. Effects of Assignment to V-SOURCE on College Persistence Outcomes

\begin{tabular}{lccccc}
\hline & $\begin{array}{c}(1) \\
\text { Any College }\end{array}$ & $\begin{array}{c}(2) \\
\text { Any 4-Year }\end{array}$ & $\begin{array}{c}(3) \\
\text { Any Selective }\end{array}$ & $\begin{array}{c}(4) \\
\text { Any CSU }\end{array}$ & $\begin{array}{c}(5) \\
\text { Any UC }\end{array}$ \\
\hline Milestones & 0.008 & 0.004 & 0.013 & -0.010 & $0.016^{*}$ \\
& $(0.014)$ & $(0.012)$ & $(0.008)$ & $(0.011)$ & $(0.008)$ \\
Complete & & & & & \\
& 0.018 & 0.018 & 0.004 & 0.007 & 0.011 \\
& $(0.014)$ & $(0.013)$ & $(0.009)$ & $(0.011)$ & $(0.009)$ \\
\hline Observations & 6,640 & 6,640 & 6,640 & 6,640 & 6,640 \\
Control Mean & 0.633 & 0.367 & 0.108 & 0.203 & 0.115 \\
\hline
\end{tabular}

Outcomes come from the National Student Clearinghouse (NSC). College persistence reflects enrollment in the specified college type in the first fall (September 1 to December 31) after on-time high school graduation AND in the same college type in the second fall. Selective colleges are those with Barron's ratings of very competitive plus to most competitive. Regression includes controls for blocking group indicators, as well as linear, squared, and cubed terms for two GPA measures; for missing values, we impute the mean and include a missing value indicator. Standard errors, clustered on school, are reported in parentheses. + Statistically significant at the $5 \%$ level after adjustment for multiple comparisons.

${ }^{*} p<.05,{ }^{* *} p<.01,{ }^{* * *} p<.001$ 